University of San Diego

Digital USD

1991-07-01

\title{
The Impact of an Integrated Study Skills Program on University of La Verne Adult Undergraduates at Vandenberg Air Force Base and Naval Air Station North Island
}

Pamela Priest EdD

University of San Diego

Follow this and additional works at: https://digital.sandiego.edu/dissertations

Part of the Leadership Studies Commons

\section{Digital USD Citation}

Priest, Pamela EdD, "The Impact of an Integrated Study Skills Program on University of La Verne Adult Undergraduates at Vandenberg Air Force Base and Naval Air Station North Island" (1991). Dissertations. 562.

https://digital.sandiego.edu/dissertations/562

This Dissertation: Open Access is brought to you for free and open access by the Theses and Dissertations at Digital USD. It has been accepted for inclusion in Dissertations by an authorized administrator of Digital USD. For more information, please contact digital@sandiego.edu. 


\title{
THE IMPACT OF AN INTEGRATED STUDY SKILLS PROGRAM ON UNIVERSITY OF IA VERNE ADULT UNDERGRADUATES \\ AT VANDENBERG AIR FORCE BASE AND \\ NAVAL AIR STATION NORTH ISLAND
}

\section{by}

Pamela Priest

\begin{abstract}
A Dissertation Presented in Partial Fulfillment
of the Requirements for the Degree

Doctor of Education

University of San Diego
\end{abstract}

July, 1991

Dissertation Committee

Susan M. Zgliczynski, Ph.D.

Edward Kujawa Jr., Ph.D.

James Manolis, Ed.D. 


\section{ABSTRACT OF THE DISSERTATION \\ The Impact of an Integrated Study Skills Program on University of La Verne Adult Undergraduates At Vandenberg Air Force Base and Naval Air Station North Island}

The problem: There have been a number of recent attempts to provide unique educational opportunities in learning strategies and study skills for adult students. A difficulty in removing the student from the classroom to provide this specialized training is that many students are unable to transfer the acquired skills back into a variety of different contexts. A second problem is removing faculty from the ongoing class and educating them in workshops that address learning strategies and study skills. Many faculty find it difficult to incorporate these skills while meeting the demands of fulfilling course content objectives.

The Research: The purpose of this study was to assess the impact of an integrated study skills program on adult undergraduates attending courses through the University of La Verne at Vandenberg Air Force Base (VAFB) and Naval Air station North Island (NASNI). The study attempted to discover whether three methodologies of an integrated study skills program differed on affective behavioral outcomes of intact groups. Data from a preliminary survey, Learning and Study strategies Inventory (LASSI) and exit survey were analyzed using a variety of statistical measures: frequency counts, multivariate analysis and qualitative interpretation. 
The Results: The academic self-concepts, or how one views oneself as a student, of business students were significantly higher than non-business students in Time Management, Information Processing, use of Support Aids, Self Testing, Motivation and Concentration in treatment groups A and B. Non-business students improved over business students in the control group. Students liked having the opportunity to sample learning strategies and study skills, but were divided on whether to have a film presentation or an instructor-led group. Faculty expressed an interest in students being exposed to learning strategies and study skills, but some faculty were concerned about integrating the study skills program into course curriculum. 
copyright $c \quad 1991$
by

Pamela Jeanne Priest

All Rights Reserved 


\section{Acknowledgements}

I wish to thank my committee members Dr. Susan Zgliczynski, Dr. Edward Kujawa Jr., and Dr. James Manolis for their continual support and enlightening suggestions throughout the development of this document.

I would also like to thank Dr. P. A. Moore for the many hours of moral support and excellent text editing. I am grateful to Dr. J. P. Amor for the endless hours of encouragement and statistical editing. A special thanks to Mrs. Wendy Wood for preparation of the final document for publishing.

I wish to thank Mrs. Evelyn Hardin, Director of the University of La Verne Residence Center at Vandenberg Air Force Base for her wonderful support. A special thanks to Mrs. Donna McCandless, office Manager and Ms. Carol Kimball, Counselor at the University of Ia Verne at Naval Air Station North Island for all of their assistance in continuing the smooth program operations during my sabbatical. Thanks too to the many students and faculty who volunteered to participate in the study, and without whose cooperation the endeavor could not have been possible.

My deepest thanks to my mother Evelyn E. Trotter and my son Jeffrey D. Priest, both of whom have been unconditional sources of love and guidance. 
TABLE OF CONTENTS

Subject Page

Acknowledgements . . . . . . . . . . . . . . ii

List of Tables . . . . . . . . . . . . . . . v v

List of Appendices . . . . . . . . . . . . . . . vii

CHAPTER ONE - Statement of the Issue . . . . . . . . 1

Introduction . . . . . . . . . . . . . . . I

Statement of the Problem . . . . . . . . . . 8

Research Questions . . . . . . . . . . . 8

Significance of the outcome . . . . . . . . . 10

Definition of Terms . . . . . . . . . . . . . 11

Assumptions and Iimitations of the study . . . . . 14

CHAPTER TWO - Literature Review . . . . . . . . . 17

Introduction . . . . . . . . . . . . . 17

Learning . . . . . . . . . . . . . . 18

Pedagogy versus Andragogy . . . . . . . . . . 21

Adult Education . . . . . . . . . . . . . 24

Curriculum Development . . . . . . . . . . 28

Study Skills Programs . . . . . . . . . . 31

synthesis . . . . . . . . . . . . . . 46

CHAPTER THREE - Research Design and Methodology . . 50

Introduction . . . . . . . . . . . . . 50

Data Collection overview . . . . . . . . . 51

Population . . . . . . . . . . . . . . 52

Sample Selection . . . . . . . . . . . . 52

Instrumentation . . . . . . . . . . . . 55

Data Collection . . . . . . . . . . . 57

iii 
Data Analysis . . . . . . . . . . . . 60

Ethical Concerns . . . . . . . . . . . 60

Mortality . . . . . . . . . . . . . 61

CHAPTER FOUR - Research Findings . . . . . . . . 63

Introduction . . . . . . . . . . . . . 63

Sample Description . . . . . . . . . . . 63

Results of Preliminary Survey . . . . . . . . 66

Results of the Pilot study . . . . . . . . . 69

Significant Findings . . . . . . . . . . . 71

Further Findings . . . . . . . . . . . . 104

Slimmary . . . . . . . . . . . . . . 105

CHAPTER FIVE - Summary, Conclusions and Discussion - 109

Introduction . . . . . . . . . . . . . 109

Findings and Future Research . . . . . . . . . 119

References . . . . . . . . . . . . . . 133

Appendices . . . . . . . . . . . . . . . . . 143

iv 
1. Frequency Counts on Part I of Opinionnaire . . . 66

2. Relationship of 9 Items on opinionnaire to 10 IASSI Scales ............ . 67

3. Grand Means and their Standard Deviations for Part II of Opinionnaire..... . . . . 68

4. Wilks' Lambda for the Pilot Study . . . . . . 70

5. Wilks' Lambda for (Full study) 4-Way MANOVA without Highest order Interaction . . . . . 72

6. Wilks' Lambda for 3-Way MANOVA: Location by Method by Time ............... 73

7. Univariate $\underline{F}$ Tests. 3-Way MANOVA: Location by Method by Time, Effect: Method by Time. . . 74

8. Newman-Keuls Post Hoc Comparisons of Pre/Post Test Differences of Methods C, B, and A on Participants' LASSI attributes 3-Way MANOVA: Location by Method by Time, Effect: Method by Time . . . . . . . . . . . . . . 78

9. Univariate $\mathrm{F}$ Tests. 4-Way MANOVA without Highest Interaction Effects: Class by Time - 79

10. Wilks' Lambda for 3-Way MANOVA: Class by Method by Time.................... 81

11. Univariate $\mathbf{E}$ Tests. 3-Way MANOVA: Class by Method by Time. Effect: Time . . . . . 82

12. Univariate $\underline{E}$ Tests. 3-Way MANOVA: Class by Method by Time. Effect: Class by Time . . 83

13. Change in Significant LASSI Attributes (Pre/ Post Test Differences) of Classes Business and Nonbusiness 3-Way MANOVA: Class by Method by Time, Effect: Class by Time ....... 86

14. Univariate $\underline{F}$ Tests. 3-Way MANOVA: Class by by Method by Time . . . . . . . . . . . . 
15. Newman-Keuls Post Hoc Comparison of Pre/Post Test Differences of Methods C, B, and A by Classes Business and Nonbusiness on Participants' LASSI Attributes. 3-Way MANOVA by Time, Effect: Method by Class by Time . . . . . . . . . . . . . . . .

16. Exit Survey Patterns by Student Participants in Groups A and B . . . . . . . . . . . . 92

17. Exit Survey Patterns by Faculty Participants in Groups A and B ................ 93

18. Grand Summary . . . . . . . . . . . 121 


\section{List of Appendices}

Page

Appendix

$\begin{array}{ll}\text { Appendix A: } & 143\end{array}$

Appendix B: Letter to Dr. Claude olney 144

Appendix C: Cover Letter to All Instructors 145

Appendix D: Cover letter to Group B Instructors 146

$\begin{array}{lll}\text { Appendix E: } & \text { Roster Form } & 147\end{array}$

$\begin{array}{ll}\text { Appendix F: } & 148\end{array}$

$\begin{array}{ll}\text { Appendix G: } & 149\end{array}$

$\begin{array}{lll}\text { Appendix H: } & \text { Iist of Directions for Group B } \\ & \text { Instructors } & 150\end{array}$

$\begin{array}{ll}\text { Appendix I: } & \text { Exit Survey Form for Students and } \\ \text { Faculty } & 151\end{array}$

Appendix J: Pre and Posttest Means and Standard Deviations for Business and Nonbusiness Classes on 10 LASSI scales

Appendix K: Pre and Posttest Means and Standard Deviations for Methods $C, B$ and $A$ on 10 LASSI scales

Appendix I: Pre and Posttest Means and Standard Deviations for the Entire Population on 10 LASSI scales

Appendix M: Pre and Posttest Means and Standard Deviations for Methods $C, B$, and $A$; and, Business and Nonbusiness classes on IASSI scales. Means for Method by Class by Time

vii 


\section{CHAPTER ONE \\ Statement of the Issue}

\section{Introduction}

America continues to backslide in the development of study skills curricula, especially at the postsecondary level. An apparent lack of awareness to students' selfperceived needs is part of the dilemma. The California Task Force (1990) said that failure to learn could be catastrophic for individuals and its costs could be staggering to society. A number of schools are failing to achieve their most basic objective--that of adequately educating young people for a rewarding and productive life. Integration of learning strategies and study skills into postsecondary course curriculum is a challenging task. Many approaches to helping adult students learn how to learn exist. Few reviewed, however, provide a comprehensive study skills program integrated into course curriculum. Most programs focus on removing the learner from the primary learning environment. The individual is taught study skills in a secondary environment and is subsequently mainstreamed back into a primary setting. A few studies encouraged integration of study skills program with course curriculum; 
but, the practitioner's efforts often resulted in limited integration (Mangen, 1988). Specifically, Weinstein developed a separate class for learning strategies and study skills for freshman as well as a faculty workshop for instructors to learn how to teach study skills, but there was nonetheless a lack of a defined, comprehensive integrated program (Mangan, 1988).

Most programs designed for adult learners fell into two major areas: A training and development program or seminar (for industry) or a basic skills course or tutorial (for college campus)

Alan B. Knox (1988), professor of Vocational Education at the University of Wisconsin at Madison, commented on the way industry developed branches of the Human Resources Department to address the development of basic skills programs. These programs were geared toward helping employees acquire the necessary cognitive and affective tools to further develop a specific area of expertise. Trainers worked with employees in special seminars which were removed from the primary work place and which focused on areas of interest of managers and employees: Several of these areas of interest, for example, addressed tasks on the job which could be evaluated by management to show progress. Trainers had several responsibilities. One was to provide feedback to the employees to stimulate self-development. Another was to analyze current performance levels against 
standard levels of performance and to set goals which would bridge the discrepancies. A third was to make sure that employees identified trainer selected goals as also desirable to employees.

Several strengths were identified with this approach in industry. One was an emphasis on improving participants' performance levels. A second was the design of an intervention program to develop participants' performance. Another was the commitment to stimulate individual initiative to apply what was learned in the seminar to their work situation.

A few weaknesses existed in the program. Too much emphasis was placed on management's need to increase service or to increase profit. Participants were removed from natural stressors which occurred on the job, such as time demands. Incentives were sporadic and unrelated.

One of the trainers for the Union Tribune Publishing Company discussed her perceptions of some of the discrepancies between theory and practice in working with adult learners. classes were traditionally held separate from the work site and the ultimate goal was the overal 1 improvement of performance of the participants for the welfare of the corporation. There were several perceived advantages to this method. One was that the learning process did not take time away from the task. Learning strategies, such as role playing, case study analysis and 
group discussion, were available in the classroom and not on the job. Additionally, it was easier to set up reinforcers in the more controlled environment of the classroom than on the line. Disadvantages were the absence of natural stressors, the difficulty in transferring knowledge acquired in the classroom to the actual job site and resistance to change (J. A. Shay, personal communication, March, 1989). on occasion industry teamed up with academia in search of a better way to train adult learners. In the mid-1980s the University of Minnesota was approached by Wilson Learning corporation to form an alliance for research and development in the area of applied learning technology (Carrier, 1987). Both entities were aware that individuals have different cognitive and learning methods. The specific concern of the project was the use of technology to teach large groups of people and still adapt instruction to meet individual needs. The approach included utilization of self-paced computer applications.

Advantages of such programs were varying levels of difficulty in computer programs and self-paced methods to meet the needs of students. Another advantage was the use of technology in reaching large numbers of students. Disadvantages were a lack of peer interaction and group discussions.

Another example of technological applications was a computer based self-assessment skills program. Brian 
Rudolph (1990) discussed the use of self-assessment procedures as an educational experience for adult learners. Rudolph focused on study programs which allowed computer professionals to analyze their concepts of concurrency, which he defined as parallel execution of multiple tasks. The procedure involved classical problems, formal topics and terminology. The result was a skills program which permitted self-assessment tools to be used with a generic intervention program that was applied to many tasks.

In the past, private industry, academia, and the combined efforts of industry and academia were concerned with meeting the needs of an increasing adult student population. Today many educators in postsecondary settings are addressing this concern. The following three programs are examples of ways in which educators are helping adult learners:

Dr. Claire Weinstein, a learning strategies expert with the University of Texas at Austin, developed a highly successful freshman course in Educational Psychology called Learning to Learn. The course reviewed basic learning strategies and study skills which focused on motivation, test taking and attitude (Mangan, 1988).

Dr. L. Kochenderfer, Director of the Learning Center for Riverside Community College, used a similar curriculum for a freshman course. One of the recurring problems she identified was the inability of some students to carry 
learning strategies and study skills concepts into mainstream courses. Kochenderfer claimed that "something seemed always to be lost in the translation" ( $L$. Kochenderfer, personal communication, October, 1990).

Dr. Claude olney, Arizona State University, used a different approach. He designed a seminar for postsecondary students on basic study skills. Olney's objective was cognitive outcome as reflected in achieving " $A$ "s in coursework. He filmed his seminar, entitled "Where There's A Will There's An 'A'" and is currently marketing the videos to private industry, to educational institutions and to individuals (C. Olney, personal communication, February, 1991).

study skills programs in academia followed the format of either seminar or freshman class. These situations removed participants from the ongoing classroom environment, placed the individuals in a simulated environment to acquire the necessary skills, then mainstreamed the subjects back into the real situation with a toolbox of devices designed to improve performance. Research and implications were that an integrated learning strategies and study skills program might be beneficial for some groups of adult students, yet obstacles remained for a completely integrated program (Weinstein, Goetz, \& Alexander, 1988).

There was a trend toward an increasing adult student population. Many of these individuals were perceived to 
have special needs and it was believed that there were unique opportunities for educators to assist these students in achieving successful academic careers (c. Grafton, personal communication, February, 1991).

There were gaps in the curriculum design of study skills programs for adult learners as well as the absence in some situations of appropriate programs all together. Study skills programs had restrictions on levels of success due to the fact that the design of these programs in industry and postsecondary educational institutions was strongly determined by what senior level managers (or senior level educators) believed to be important (Knowles, 1984). study skills programs were seen to be more effective when managers and educators supported innovative ideas and were responsive to learners' aspirations (Weinstein, Goetz, and Alexander, 1988). One study (Knox, 1988) showed that a most effective way to encourage the adult learner was to find out what was perceived as important and then respond to that perception. By responding to the intensity of individuals' feelings regarding self, work, and school, educators effectively evaluated individuals' values, attitudes and beliefs. Educators designed study skills programs in which students wanted to participate. The programs developed and aligned goals and made application of skills easier (Knox, 1988). 
Reinforced with strong study skill habits achieved through a concurrent ongoing curriculum of courses with built-in study skills component, adult students could move into graduate programs and society with increased self confidence. Elevated self-efficacy beliefs led to a stronger conviction that the individual was a capable person (Bandura, 1982). This also concluded in not only a higher grade point average, but an interest in a new subject area which the individual might wish to pursue. There currently exists the possibility that producing more capable individuals can contribute to the development of a more literate global society.

\section{Statement of the Problem}

The purpose of this study was to assess the impact of an integrated study skills program on adult undergraduates attending courses through the University of La Verne at Vandenberg Air Force Base (VAFB) and Naval Air station North Island (NASNI). The main question the research addressed was whether three methodologies of a study skills program built into course curriculum differed on their impact on affective behavioral outcomes of intact groups.

\section{Research Questions}

Research questions which this study investigated follow: 
1. Was there a significant difference in change over time in mean LASSI scores among three presentation methodologies?

2. Was there a difference in change over time in mean LASSI scores between traditional and nontraditional adult students?

3. Was there a difference in change over time in mean LASSI scores between business and nonbusiness courses?

4. Was there interaction between intervention method and traditional versus nontraditional student over time?

5. Was there interaction between intervention method and type of class over time?

6. Was there commonality between constructive comments addressing the overall study skills program?

7. Was there commonality between what was liked the most in the overall study skills program?

8. Was there commonality between what was liked least in the overall study skills program?

These research questions were investigated with three groups of adult undergraduate students enrolled in University of La Verne programs at Vandenberg Air Force Base (VAFB) and Naval Air Station North Island (NASNI). The population for the study and the methodology are addressed in detail in Chapter Three. 


\section{Significance of outcome}

The crisis in study skills development at the postsecondary level must be addressed in order to help college students develop to their maximum performance levels. One way to offer insights in how this may be accomplished is to have periodic reviews of needs assessments focusing on this issue.

The roles which educators of adult students play in helping this very diverse population achieve a college education must be acknowledged in the attempt to produce a strong base of informed workers within society. In addition, these students would be prepared through efficacious study skills programs so that they may gain the greatest benefits from the courses in which they are enrolled.

Effective study skills programs are those in which the adult students reflect on the self-efficacy belief systems which govern their levels of interest in college work. Continual reevaluation of any self-defeating behaviors which interfere with their college success begins to be a part of their thinking processes. As the behavior changes, the mind continualiy reevaluates the new performance levels and the background assumptions affecting the evolving belief systems.

Investigations between study skills programs and adult student efficacy in college work could be beneficial to both 
domains. Through periodic needs assessments and trial study skills programs educators could become better informed regarding the areas in which students feel deficient as well as those programs which are better suited to one group of students over another. In fact, long term planning by educators can enhance what classroom instructors facilitate in the learning process by encouraging effective built-in study skills programs, which may prove to be more successful to long lasting change as opposed to a one time endeavor (Bimes-Michalak, 1988).

Educators are concerned about providing the best of possible learning environments for adult students. This is of particular concern to university accreditation associations. These periodic accreditation reviews can promote university initiative to review and develop programs which enhance the learning experiences of the adult student.

\section{Definition of Terms}

Definitions of key terms are given in order to provide meaning and aid in the interpretation of data for the study.

Traditional Adult student. Adult students participating in the investigation of the impact of an integrated study skills program in course curriculum were divided into two groups by the year of birth. Traditional students were those between the ages of 18 and 25 . (Those subjects born after 1966.) 
Nontraditional student. Adult students who were 25 years of age or older. (Subjects born in 1966 or earlier.) Study skills program. Eight 20-minute video tapes of the film "Where There's A Will There's An 'A'".

Treatment. Those participants in method group $A$ or method group B who were exposed to six or more of the video sessions in the study skills program.

Method Group A. Those participants viewing the study skills program and having no manual or group discussion following the video.

Method Group B. Those participants viewing the study skills program and having a manual on study skills and also having a group discussion following the video.

Control Group Method $c$. Those participants having none of the following: The study skills program, manual or group discussion.

IASSI. The Learning and study Strategies Inventory which measured a student's self-perceptions toward college success and which was used as the pretest and posttest in all three methods $A, B$, and $C$. ISSI Scales. The ten scales are: Attitude, Motivation, Time Management, Anxiety, Concentration, Information Processing, Selecting Main Ideas, Support Aids, Self-testing, and Test Taking. 
Roster. Student attendance records during the term to identify which students were exposed to the study skills program.

Consent Form. Participants in the project signed forms stating that they were voluntary subjects.

Faculty Meetings. The researcher met with faculty who were participating in the study either individually or by appropriate group (e.g., A, B, or C) and discussed specifically what their role would be in the study.

Method "B" Instructors. These instructors were given special instructions and a demonstration on both use of the study skills manual as well as how to lead group discussions which would challenge a student's background assumptions on study skills and college success.

Study Skills Manual. A booklet produced with the video "Where There's A Will There's An 'A'" and covering 20 study skill techniques which the film addressed.

Business Classes. The following classes were grouped in this category: Principles of Management (VAFB, Group A), Cost Accounting (VAFB, Group B), Legal Enviromment of Business (VAFB, Group A), Macro Economics (NASNI, Group B), Auditing (VAFB, Group B), Computer Applications in Business (NASNI, Group B), Labor Management Relations (VAFB, Group A), Principles of Retailing (VAFB, Group C) and Management Information systems (VAFB, Group C). All of the above classes were upper division with the exception of Macro 
Economics. All but three students in the above classes were business majors. (None of the business classes' curricula addressed issues measured on the ten IASSI scales.)

Nonbusiness classes. The following classes were grouped in this category: Juvenile Delinquency (NASNI, Group A), Science and Society (NASNI, Group C), Art and Civilization (NASNI, Group C), which were all upper division; and, World History (NASNI, Group A), General Sociology (NASNI, Group A), College writing (NASNI, Group B), Communication Skills (NASNI, Group C) and Axt Experience (NASNI, Group C), which were all lower division. The students in these classes were either undeclared majors, social science majors or working toward an Associate of Arts in General studies. (None of the non-business classes' curricula addressed issues measured on the ten LASSI scales.)

Maonitude of Change. For the purposes of this study, this is a combination of sample size, the range of the variance, and the mean change on IASSI pre test posttest differences.

\section{Assumptions and Iimitations of the Study}

This research study used a quasi experimental design with three intact groups. The groups differed in that one group was a control group and received no treatment. Participants were pre and posttested. The second group "A" 
was a treatment group where the method was to have the participants watch a study skills program and were administered a IASSI pre and posttest. The last group was a treatment group where the method was to have participants watch a study skills program, refer to a study skilis manual, and have a group discussion with the instructor. The instructor was advised to follow specific steps in leading the discussion. The lack of pure random selection may have biased the results and was an inherent weakness in the intact group design. Although group B instructors were given specific guidelines to follow as well as a demonstration on how to follow them, there may have been biased results due to personality differences among the instructors as group B discussion leaders (for example, some instructors may have been more positive and enthusiastic in their delivery and others less excited about the study).

Another assumption was control for researcher bias in design and methodology. The use of surveys and quantitative instruments administered by others allowed for no interference by the researcher during administration or testing. However, researcher interpretation of the data reported in discussion sections may have been biased since the researcher was the administrator of the Naval Air Station North Island University of La Verne programs. It is hoped that unintentional bias has not interfered with the conclusions drawn from the study. 
An assumption on the part of the researcher is that multiple analysis of variance (MANOVA) is one of the most powerful inferential statistical tools available for educational research. Variance cannot be emphasized enough in educational research, since education involves one of the most complex fields of behavior. In this field it is important not only to consider more than one variable at a time, but also to consider the subtle interactions between an array of variables (Popham, 1967).

A limitation, however, is that three or more variables produce extremely complex interaction effects. Not only are there main effects of each independent variable on the dependent variable, but there are also interaction effects of each independent variable with each independent variable. 
CHAPTER TWO

Review of The Iiterature

\section{Introduction}

Study skills programs have been slow to develop over the years. Early efforts focused on separate, remedial programs for elementary-aged children, and more recent efforts in the 1970 s and 1980 s expanded study skill activities into the junior high school levels with an emphasis on reading and math. The rationale for the more recent tutorials was preparation of students for high school. Programs developing students' study skills moved into the high school and first two years of college in the 1980s and early 1990s. The trend was toward an integrated and sequential program of study skills in course curriculum. These programs operated through continuous cycles of needs assessments, development and implementation, evaluation, redesign and further implementation.

The brief literature review that follows is divided into five broad topics, which are relevant to the development of study skills programs in postsecondary education. First, a short chronology of several dominant 
learning theories which developed in the past 30 years are mentioned, then select views on adult education, and curriculum development are reviewed. Next, the development of exemplary study skills programs at the secondary and postsecondary level during the past five years are looked into; and finally, the specific study skills program and instrument of measure for this study are discussed.

\section{Learning Theories}

One of the highly significant theorists of the past thirty years was Bloom, who determined that learning could be organized into three categories:

1. Cognitive, which deal with the recall or recognition of knowledge and the development of intellectual abilities and skills; 2. Affective, which describe changes in interest, attitudes, and values, and the development of appreciations and adequate adjustment; and, 3. Psychomotor, which deal with coordination. (Bloom, 1956, p. 7)

Bloom found that with physical growth and knowledge change occurred in each of these areas.

Many theorists in the field agreed that learning involves change in the individual. Early experts broadly defined the learning process with changes in behavior, for they observed that as individuals interacted with their environment a number of social and personal adjustments were 
made to assure ongoing need fulfillment (Crow and Crow, 1963; Burton, 1963; Haggard, 1963).

Gagne (1965) contended that behavioral change was either developmental or planned. Developmental change was an aspect of the process of physical growth and continual maturation in his opinion; whereas, planned change was the result of adjustments in levels of capability to handle tasks, and human attitudes toward tasks.

Gagne's concept was further developed by Bruner (1966), who stated that not only is change developmental, also it is competency based. Jones (1966) felt that Bruner's theory of learning was too narrow. He believed Bruner's theory underemphasized emotional elements and excluded the intellectual processes of concept formation and invention.

A new approach to learning surfaced in the late 1960s with B. F. Skinner (1968). He believed that learning involved control and shaping. Skinner's position was behavior could be modified by reward or punishment.

The early 1970 s opened a new viewpoint on learning referred to as humanism, which is credited to Abraham Maslow. Maslow (1972) envisioned a holistic selfactualization as the ultimate process of learning. He described this synergistic phenomena as a hybrid of the tensions created by a polarity of forces within the individual. He depicted one force as drawing the individual toward the past, encouraging a defensive clinging out of 
fear. The other force was viewed as driving the individual forward in an adventure of discovery toward the realization of the seif and the uniqueness of that self. Maslow concluded that one can only move forward when the happiness of exploration and growth are greater than the anxieties of fear; and, when the joys of feeling safe in a rationalized memory are unmasked (Maslow, 1972).

In the late 1970s and into the 1980s, three main views of learning were prevalent: quantitative, qualitative, and behaviorist (Mayer, 1988). The quantitative looked at "how much" one learns. There were four aspects to this first model. The learner receives instruction which is processed as incoming information. The learner's memory encodes parts of the information to be used in future problem solving. Qualitative learning looked at four elements as well. Its premise was that the way in which a learner processes information determines the learning outcome. The last model, behaviorist, asserted that a learner's performance on a posttest was directly related to how much instruction was received, and the model totally ignored learning process and outcome (Mayer, 1988).

The commonality which appeared among the above traditional theories on learning was an agreement that the individual changes as the learning process unfolds. This learning process occurs when the individual takes in information, analyzes the data, acts in terms of the new 
data, then evaluates the action in the light of need fulfillment. The learning process although somewhat generic is also linked with learning styles. In recent years, efforts have been made to understand and describe the elements of learning styles and these efforts have been called critical pedagogy (Greene, 1986). Pedagogy was broadly defined as the art of teaching; however, in recent years a distinction has been made between pedagogy and a more recent theory of adult learning called andragogy.

\section{Pedagogy Versus Andragogy}

Studies of animals and children have contributed to modern views of learning (Knowles, 1970, 1984, 1989). Schools and institutions where children and young adults attend regularly have added to the body of knowledge on teaching and teaching techniques. Since the main view of teaching has emphasized the transmission of the culture, the word "pedagogy" has come to be associated with the art of teaching children (ped - child; agogos - learning) (Knowles, $1970,1984,1989$ ).

Young adults, ages 18 to about 25 , are a bridge between the child and the adult and have overlapping needs. Additionally, they are viewed at one end of the adult continuum which addresses the developmental needs of forming a strong social group, selecting a mate, starting a career, and starting a family. They are described further as the 
traditionally-aged college students, thus the "traditional adult" student. Many aspects of the pedagogical approach to teaching are applicable to this age group, whose primary role is that of student.

Many nontraditional adult students, students aged 25 and over, have married, some have started a family, and many are in mid-career by the age of 25. Many are also part-time students attending classes at night (Hood, personal communication, October 15, 1991).

Knowles (1984), a leading authority in adult learning styles, argued that it is impossible to teach adult learners exactly the same as one would teach children. There are critical, distinguishing factors in learning styles between children and adults. Children are required by law to attend school, but adults' attendance is usually voluntary. Children look to teachers as undeniable authorities who will impart truth, whereas adult students weigh an instructor's authenticity against the adult student's own life experiences in the world of work. Children learn out of different motivational drives than adult students. The recognition of this difference has resulted in "andragogy," the art of teaching the adult (from andr -man) (Knowles, $1984,1989)$.

Andragogy assumes four aspects of the adult learner. Self-directedness as an element of adult students' selfconcept results in their resistance to engage in learning 
activities which infringe on individual autonomy. The adult students' accumulation of experience is a valuable resource in the learning process and is expected to be utilized by the instructor (Knowles, 1970, 1984; Mayer, 1984). Adult students anticipate that curriculum design will be aligned with the developmental stage in which they are; and, there is a strong need to directly relate theory to application of problems similar to those which the adult students face. There are three background assumptions of the andragogical teaching approach. Instructors need to believe that adults can learn throughout the life span. Teachers need to acknowledge that adults are motivated primarily from within. There needs to be a specific learning environment which is more conducive to the developmental stage of the adult (Chickering, 1976; Cross, 1981; Knowles, 1970, 1984). Superior conditions which Malcom knowles (1970) found to facilitate learning for adults follow:

- The learners feel a need to learn;

- The learning environment includes physical comfort, mutual trust and respect, mutual helpfulness, freedom of expression, and acceptance of differences;

- The learners perceive the goals of a learning experience to be their own goals;

- The learners accept a share of the responsibility for planning and conducting the learning experience and have a feeling of commitment to it; 
- The learners participate actively in the learning process;

- The learning process is related to and makes use of the experience of the learners: and,

- The learners have a sense of progress toward their own goals.

In summary, pedagogy addresses teaching techniques to relate to the learning styles and developmental needs of children, whereas andragogy focuses on teaching practices that address adult student's wants and needs. Since young adults ages 18 to about 25 are predominantly full-time college students in a traditional main campus setting, they are viewed as "traditional" adult students. Those individuals who are 25 and over and whose primary function is worker and part-time student are called "nontraditional" adult students. Although the traditional students may bridge childhood and adulthood, often a more pedagogical approach to teaching is effective. The nontraditional adult students are more responsive to an andragogical approach, because they are self-directing, self-actualizing and depend upon their experiential base to enrich their learning experience.

\section{Adult Education}

Society has long been concerned with educating adults. Little research has focused on this issue until more recent 
times. The primary modes of educating adults--Andragogy-were predominately through the case studies approach, the use of parable, and the socratic method (Knowles, 1984). Highlights of a few of the twentieth century events that moved adult education ahead follow.

In 1926 the American Association for Adult Education (AAAE) was founded and monies were made available through the Carnegie Foundation. The AAAE became the catalyst for the development of two areas of inquiry on educating adults. A leader in utilization of the scientific approach to educating adults was Edward Thorndike. His series of publications: Adult Learning, (1928), Adult Interests, (1935), and Adult Abilities, (1938) clearly pointed out that adults were quite different from children in the values, interests and abilities areas (Knowles, 1984).

A proponent of the artistic school of how adults learn was Eduard Lindeman, who was dramatically influenced by John Dewey's philosophy that learning is acquired experientially. An excerpt from Lindeman's book The Meaning of Adult Education, (1926), demonstrates an emphasis on experiential learning.

The approach to adult education will be via the route of situations, not subjects. Our academic system has grown in reverse order: subjects and teachers constitute the starting-point, students are secondary. In conventional education the student is required to 
adjust himself to an established curriculum; in adult education the curriculum is built around the student's needs and interests. Every adult person finds himself in specific situations with respect to his work, his recreation, his family-life, his community-life, et cetera--situations which call for adjustments. Adult education begins at this point. subject matter is brought into the situation, is put to work, when needed. Texts and teachers play a new and secondary role in this type of education; they must give way to the primary importance of the learner. (Lindeman, 1926, Pp. 8-9)

one of the principals of Manchester college in oxford England wrote his ideas of adult education in the Journal of

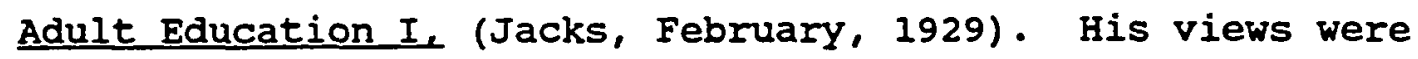
that adult education must be a process not an end in itself. Educators must hold a "vision of continuity" (Jacks, 1929, pp. 7-10). The evolving adult is always in a state of becoming. There must be a theme of education weaving the ideas of learning in with vocation. Just as the individual changes and becomes, so does the state.

At the risk of seeming fantastic I will venture to say that the final objective of the New Education is the gradual transformation of the industry of the world into the university of the world: in other words, the gradual bringing about of a state of things in which 
"breadwinning" and "soulsaving" instead of being, as now, disconnected and often opposed operations, shall become a single and continuous operation. (Jacks, 1929, pp. 7-10)

Another view on what it is to educate adults came from James E. Russell, Dean Emeritus, Columbia University. In his opinion, educators can provide the classroom, textbooks, curriculum and supporting materials; however the student, viewed as the climber "must use his own head and legs if he would reach the mountaintop" (1938, pp. 385-386). Russell emphasized the need for group discussion after presentation of concepts to reinforce what has been presented; and, to enable the student to develop application and synthesizing abilities (Iindeman, 1938, pp. 385-386).

As concluding remarks, the above perspectives presented a variety of views on how to best educate the adult; and, many of the techniques are still professed to work and are in use today (Knowles, 1984). Case study approach, the use of parables and aspects of the socratic method are used in curriculum from business to psychology. The adult student curriculum emphasizes a more integrated approach which draws theory into application to best meet the needs of the developmental phase of the adult student. 
Curriculum Development

Ideally, curriculum is designed with the active involvement of all the participants. This includes (in the area of adult education) the adult students, teachers, administrators and anyone else who is a stakeholder in the unfolding process. The grass-roots approach to designing the plan tends to facilitate the actual implementation process. An early curriculum specialist, Mildred J. Wiese, touched on an aspect of this phenomena several decades ago. The needs of their students are foremost in the minds of most instructors and they look for assistance in setting up programs consistent with those needs. Instructors desire to keep a degree of flexibility in their courses so that they can keep up with the varied interests of their students; and, most instructors want to make their courses relevant to their students' daily life experiences. Instructors seek spontaneous opportunities to enrich theirs and students' programs, and ones which will draw application to their students' real life day-to-day activities (Weise, 1939).

Weise (1939) continued to discuss the need teachers have in leading a group without dominating it; and, to provide ample opportunities for sicudents to become more responsible for planning their own activities for study and classroom participation. 
Hans Van Der Meij (1991), at the other chronological end of curriculum development, suggested that one key to effective leading is built on the concept of understanding as a way to effective questioning and teaching. It is through the dialectic of question and answer that learning takes place and goals or visions are formulated and realized.

He contended that one needs to see the question as a whole consisting of three aspects "assumptions, questions and answers"; that is, to see the two "faces" each question displays. One face is content of the sentence and the social-communicative manner in which it is presented and the other face is what makes the process of questioning difficult on a one to one basis, as well as highly complex in the group discussion. One face of the question often masks the other. Yet, group discussion involving effective questioning provides a synergistic stimulus for learning, because of the process of immediate application to current problems. It also helps in "identifying and challenging the assumptions by which we live" and "is central to thinking critically" (Brookfield, 1987).

The solving of problems requires both a solid knowledge base and creative thought processes, which lend themselves to critical thinking. one obstacle to thinking critically is that one organizes information and perceptions in a way that gives meaning to the world. Meyers (1986) argued that 
as a result, one clings to maintaining the structures, or paradigms, in which one has a vested interest, and which makes sense for one's own existence. Yet, one must free oneself from the self-imposed prison of a paradigm and challenge assumptions which are preventing the solution to complex problems, if one is to learn and to survive. wlodkowski (1985) contended that to do so is extremely difficult and resistance is high, because to challenge one's assumptions about the world is to risk the unknown and possibly confront failure. Egan (1986) agreed that critical reflection is essential for survival, since it is only through accepting this challenge that alternative visions are possible. Critical thinking needs to be taught, rehearsed and reviewed (Anderson et al., 1981).

Many educators assumed that students somehow acquired study skills for problem solving naturally as they progressed through school (Brown et al., 1983). Mezirow (1990) contended that is not the case, but rather students process information which fits within their paradigm, or they reject it. Argyris $(1976,1991)$ felt that individuals tend to function with single-loop learning schemes in which they find an error and go back and correct it, rather than solving problems at a more complex level. Although in a number of instances single-loop learning is desirable, highly complex problems require double-loop learning, which involves identification of the origin of the problem, rather 
than correction of the symptom alone. It is through the exercise of double-100p learning that "doom loops" (espousing one set of actions and executing a different set of actions) can eventually be broken, and a greater congruence between thought and action can be achieved (Argyris, 1991). This process of critical reflection can be used in the curriculum of study skills programs. When students are experiencing academic difficulty, they can be taught to question the way in which they study and seek the development of alternative strategies by which to study.

\section{Study skills programs}

study skills programs have emerged in two dominant areas: Private industry and education. In both of these areas there was a trend to remove participants from the real work experience or classroom environment, to train them in basic study skills related to success on the job or in academia, and to place the trained participants back into the real job or class with a new collection of skills. The hope was for performance success. Knox (1988) pointed out that this design had advantages and disadvantages, of which the more significant was the reality that the selection of necessary skills was usually made by the manager or educator with little input from the employee or adult student. Knox's (1988) suggestion was to make the participants the focal point of the design. The following briefs of articles 
touch on some of the things which managers and educators have attempted in the area of specialized study skills to help employees and students.

In the mid-1980s, the University of Minnesota and Wilson Learning Corporation formed an alliance in the attempt to use technology to further meet the educational needs of the adult student. The goal was to teach large numbers of people simultaneously and still adapt the instruction to the particular cognitive styles of the individuals. The use of the computer was addressed (Carrier, 1987). One concern with the over reliance on technology, was an imposed limitation on the amount and degree of group discussion and peer interaction which often produces a synergistic learning experience. Both as early as Weise (1939) and as recent as Van Der Meij (1991), evidence has suggested that teachers and students are concerned with being more effective in facilitating the learning process through group discussions with evolving questions and answers.

Suzanne Saxe (1988) studied how adult learners in an industrial training program were affected by varying degrees of peer interaction. The conclusion was that moderate amounts of peer interaction during a training program are necessary for optimal achievement. This indicates that adult study skills programs might be more effective with some peer interaction on the part of participants. 
Malcolm Knowles (1989) believed that learning resistance in training programs could be overcome when teachers and trainers provided effective role models for employees and students. Knowles further argued that trainers and teachers could increase administrative involvement in special training programs by giving support to human resources development departments, educational policy makers and administrators on the need for proper training in order to assure future success on the job or in the classroom. Change is difficult and resistance can be strong for, as Machiavelli (1974) noted the innovator will find support from those who are disenchanted with the current situation and only mildly willing to put effort forth to bring about a new idea; and, strong resistance from those who have survived and are comfortable with the status quo.

So how do leaders influence organizations to initiate a training or study skills program? Some hire consultants. Organizations by nature tend to be conservative. Taft (1991) wrote of the survival rate of innovative academic programs initiated by consultants that most programs cost campuses millions of dollars and are only short-lived. A more economical and effective way might be to initiate change from within.

The use of a series of brief strategic interventions (Amatea \& Sherrard, 1991) initiated from within the 
organization could bring about more effective change. The authors viewed human patterns of interaction as systems of information that sometimes establish and function with negative feedback loops which perpetuate chronic, stagnating or crisis-oriented situations. The short-term problem oriented approach discussed in the article focused on engaging all participants--school administrators, teachers and students--to solve affective domain situations in which students cannot or will not change. It may also be applicable to institutional situations in which innovative ideas or programs are met with stone-wall resistance and top administrators look to outside consultants for solutions to their dilemmas. By initiating change from within, administrators and teachers might set role models that signal an openness to creativity and learning as well as new ways of knowing and seeing.

Dale Feuer and Beverly Geber (1988) stressed the importance of recognizing the difference in learning styles between child and adult student. They claim that andragogy has been under attack for not being basically that different from pedagogy. They reiterate knowles' postulate that andragogy has four corner stones: Adults need to be selfdirected, they learn experientially, they learn from problem-centered situations, and they are self-actualizing. However, Knowles agreed that many other variables influence learning as well (Knowles, 1984). 
Wang, Haertel and Walberg (1990) in a comprehensive overview and synthesis of investigations on variables related to the process of learning, which included affective outcomes, concluded that the primary variables were student, classroom, home and community. Mager (1968) felt that the key issue to effective learning on both the part of the student and the teacher, who directly influences a large part of the classroom environment, was attitude toward learning. His argument was that the least educators could have as an "objective of instruction is the intent to send students away from instruction with at least as favorable an attitude toward the subject taught as they had when they first arrived" (Mager, 1968). Mager continued to argue that most teachers hope that what they have to impart is important enough that the students will use the information in the future to make not only a better life for themselves and their offspring but society at large.

A three-prong approach to assure the transfer of skills was suggested by Kerner (1991). He contended that learning skills in the classroom and then applying them, or making application to another situation is a complex process. Structuring Expectations involved clarification of what learners are expected to do, focused on affective rather than cognitive domains, had carefully timed learning components, had realistic and doable expectations, held firm to expectations and got the learner to buy into the idea. 
Improving skills focused on learning objectives, held these objectives to the correct level in the coglitive domain, held firm to the objectives, kept the change unit large enough, and integrated the approach of training/education with the individual's natural environment (classroom or work site). Establishing Rewards involved making sure that the learners make immediate application of the new skill and that application of the new skill is not only externally rewarded but that the individual develops intrinsic reward from having practiced at and mastered the new skill. Developing a study skills program had to take into consideration the recipient of such a program--the adult learner, the environment in which the learner would be placed, the classroom, and the wide range of recognized variables that contributed to a successful learning experience. Since there are an infinite number of variables which contribute to successful adult learning, selection of variables had to be made of those of most interest to the researcher. The independent variables would be methods of presenting a learning skills program, type of student, type of class, and how these aspects were affected by time. Several study skills programs were reviewed prior to selecting one which was already in existence; and selecting a valid and reliable instrument by which to measure its effectiveness. 
Dr. Claire Weinstein, University of Texas at Austin, had pioneered study skills strategies for the young adult student, who was traditionally a full-time student between the ages of eighteen and under twenty-five (Weinstein, personal communication, October, 1990). She developed a course to stimulate the love of learning in incoming freshman and further developed concurrently an instrument to use as a pre and posttest to measure achievement along ten affective scales. The Learning and study strategies Inventory (LASSI) is discussed at length toward the end of this chapter. Dr. Weinstein also developed and implemented faculty workshops to teach faculty how to teach study skills. The desire was that the faculty would go back into their classes and integrate the information into their course curriculum. The resulting separate study skills course for freshman, a Learning center, and faculty workshops turned out to be typical scenarios for postsecondary educational settings.

A brief review of high school study skills programs offered separate insights. Wilson (1988), a superintendent of schools in a public school system in Texas, wrote about his experience with high school study skills programs. He found that the majority of high school students who fell short of academic success were highly deficient in organizational and information processing skills. These problems surfaced in transition from junior high school to 
high school. After reviewing students' needs assessments, he spent a year in curriculum design. Staff members were selected to implement a study skills course. They found that there was a lack of study skills programs designed for high school and only a few were designed for freshman college students. Nevertheless, the staff designed their own course, which turned out to be quite successful. Program success was believed to be due to the program having been initiated and endorsed by the executive level administrators, e.g., Board of Trustees and Central Administration. The course became a required ninth grade class and focused on memory and concentration, organization skills, speed reading, test preparation, attitude and goal setting, library research, study aid utilization, critical thinking, listening and vocabulary building. The success of the program was measured by high school gains on nationally normed achievement tests by students who took the study skills course. Affective outcomes were evaluated by exit interviews of teachers, students and parents at the end of the year.

Mrs. Margaret King of University of San Diego High school was interviewed regarding the current integrated program which this private high school is using. The program began in 1989 and was designed by Sensa Corporation, an education research and development firm. The organization provided a manual on study skills, along with a 
number of handouts; and, they also provided faculty workshops during the summer months when most students were on summer leave. The strength of the program was that it was integrated into course content and the material was presented sequentially. Not all courses had the study skills program integrated, but rather only select courses at respective levels, i.e., freshman, sophomore, junior and senior (King, personal communication, August, 1991). Sister Rose Schmidt was the Sensa trained facilitator who conducted the faculty workshops during the summer months at this high school and our Lady of Peace Academy, a private girls' high school in San Diego. She agreed that the integrated, sequential aspect of the study skills program was highly desirable and qualitative feedback was very supportive of the program. However, she also identified several weaknesses. Sensa had attempted to measure the success of the program quantitatively by designing a pre and posttest. This instrument lacked content and construct validity--one example was that a good number of the sentences to which a student might answer yes or no had Iittle association with the material covered in the study skills course. By and large, there were just as many students at the bottom and top of the grading range at the conclusion of the program as there had been prior to the program; although, there was some upward movement of the group in the middle. Another concern was expressed by 
faculty on how they were going to manage to crowd one more thing into an already crowded curriculum (Schmidt, personal communication, September, 1991).

Mrs. Nancy Shirley, Director of Operations for Sensa Corporation, agreed that these problems had been identified and Sensa was currently working on addressing the need for a valid and reliable instrument to measure program success (Shirley, personal communication, September, 1991). Since Sensa Corporation did not have anything developed for the traditionally aged college student, nor the working adult student, further investigation was conducted to find an alternative type of study skills program.

\section{The Video "Where There's A}

Will There's An A"

Dr. Claude olney, a professor at Arizona state University, had been faculty with the school for a number of years when his oldest son applied for admission and was turned down. His son was very dismayed and Dr. Olney was challenged to help his son enter and do well in college. They began reading everything on study strategies and study skills. Dr. Olney attended a number of seminars on test taking, concentration, and study skills techniques. As they progressed, both he and his son discovered that many of the suggestions on improving study skills were contradictory, 
for example, review for tests the night before class and get a good night's sleep. Out of frustration and the desire to succeed, Dr. Olney began putting together his own seminar and testing the techniques out with his son (Olney, personal communication, February, 1991).

The one-day seminar which Dr. Olney constructed covered 20 study skills techniques:

1. Think of your college career as big business.

2. Select courses you like.

3. Gather information on instructors and find out who is enthusiastic, knowledgeable and so forth prior to enrolling.

4. Read textbook material prior to class meetings.

5. Push yourself extremely hard the first two weeks to overcome the learning curve.

6. Never miss a class.

7. Ask about extra credit work and do it.

8. Review old test material prior to taking major tests.

9. Learn how to become an expert test taker.

10. Learn specifics for developing perfect papers.

11. Take advantage of registration tricks.

12. Develop and use your memory and improve concentration.

13. Get part-time jobs, scholarships and grants.

14. Use post cards or phone calls for grades. 
15. Schedule study time to your biological clock - as a motivational technique.

16. Be prepared to bail out.

17. Build your own library.

18. Use your imagination.

19. Take notes.

20. Stay mentally, physically and spiritually fit. These 20 techniques, when practiced, have brought success to students experiencing academic difficulty--including Dr. Olney's son who did get into ASU and graduated with honors.

The seminar was open to any college students, or anyone else, who was interested in learning how to do better in college. Based on the success of these seminars and the feedback from many students who attended them, Dr. olney decided to make a video and publish a manual for classroom and home use for students and faculty at other colleges and universities. This was the video and manual which was selected to become the study skills program for the working professional, evening adult student enrolled with the University of La Verne at Vandenberg Air Force Base and Naval Air Station North Island. 
The Learning And study strategies

Inventory (LASSI)

Many institutions have designed programs to enable academically deficient students to improve in college preparation (Noel \& Levitz, 1982). These programs have focused primarily on the basics of reading, writing and math. However, there are other skills needed for success in college. For example, students need to know how to learn and how to monitor their own progress (Weinstein, Ridley, Dahl, \& Weber, 1988). Often teaching students study skills will help them improve dramatically in processing new information and building self-confidence (Dansereau et al., 1979, 1985). Claire Weinstein, Stephen $\mathrm{Zimmermann}$ and David Palmer (1988) have pioneered research in developing learning strategies to help college students, and they have developed an inventory to enable them to measure the success of their efforts as reflected by student performance and perception. The Learning and Study Strategies Inventory (LASSI) was designed to assess a wide range of topics related to study skills, to identify overt and covert behaviors related to success in learning, to reflect state of the art research in learning, and to diagnose, in a pre/posttest design, learning deficiencies (Weinstein, 1987). It was designed to be used at the high school or college level. 
Drs. Weinstein and schulte reviewed many study strategies inventories, manuals and a variety of programs which enabled them to form the initial categories for the IASSI; and, they established an item pool from this research. Two major sources for items were the state-Trait Anxiety Inventory (Spielberger, Gorsuch, \& Luschene, 1970) and Test Attitude Inventory (Spielberger, Gonzalez, Taylor, Algaze, \& Anton, 1978). An initial pilot was run using a true/false format and 291 items. The inventory was divided into three parts and participants were asked to complete one of the three parts. A social desirability scale developed by Crowne and Marlowe (1978) was included to evaluate responses, and a questionnaire was given to subjects after completing the test. Test results were correlated with student's GPAs, since it was thought that this would measure study skills. Based on the data and feedback from participants, the LASSI was redesigned (Weinstein, Zimmerman, \& Palmer, 1988).

The reformatted LASSI had 149 items in a five-point Likert-type scale format. These items were recategorized by expert judges and divided into 14 categories, and a secono pilot test was run. Based on feedback from students, the inventory was again revised and the item pool diminished by 19.

Reliability was built on a test-retest format. Ninetysix participants meeting in groups of seven to 25 for two 
separate one-hour sessions, several weeks apart, had 45 minutes in which to complete the test. Six subjects dropped out and were eliminated from the data. The reliability correlation coefficient for the total test was .88, extremely good (Anastasia, 1976; Weinstein, Zimmerman, \& Palmer, 1988).

Ten scales using 90 items were constructed. These scales focused on various groups of study skills. Items were grouped by expert judges according to themes. A third pilot was run with 850 incoming freshman at a small private university in the East (Weinstein, zimmerman, \& Palmer, 1988).

The most current version of the IASSI has 77 items and ten scales. Validity was established through several measures.

For example, scores on the Information Processing scale of the LASSI have been correlated with scores on the Elaborative Processing Scale of Schmeck's Inventory of Learning Processes (1977) $(r=.60)$. Second, several of the scales have been validated against performance measures. For example, scores on the selecting rain Ideas scale have been compared to students' scores on selecting main ideas from texts and other readings ( $r=.40$ and above). (Weinstein, Zimmerman, \& Palmer, 1988, p. 35) 
The LASSI is continually reviewed. Ongoing research focuses on the validity of scales, group norms, reporting forms and formats, student profiles, and development of additional items for scales with less than ten items.

One critique of the IASSI (Mealey, 1988) suggested that it could be a useful tool in the assessment of a study strategies or reading component.

Administered at the beginning of such a course, the LASSI may provide insights into students' self reported academic strengths and weaknesses coupled with their academic self concept, a generally neglected area of concern. Strategy training might proceed with this information for each student. At the end of the course, the IASSI could be readministered to guage students' improvement as well as possible course effectiveness. (Mealey, 1988, p. 384-85)

\section{Synthesis}

An understanding of twentieth century learning theories provides the foundation for insight into the development of learning skills programs for adult students. Two predominant theories were behaviorism and humanism. skinner, the leader in behaviorist theory, advocated the use of reward and punishment in shaping individual behavior. Maslow argued that individuals have the power to become self-actualizing once their basic needs have been met. 
Teaching and learning skills developed largely by what was observed in the classroom through the education of the child, and it was called pedagogy, or an imparting of the societal and cultural values from the adult generation to the offspring. The education of the adult was referred to as andragogy.

Young adults between the ages of 18 and $25 \mathrm{fell}$ in between the much directed teaching of youngsters and the self-directed and experiential education of adults over 25. Young adults, ages 18 to 25 , were referred to as traditional adult students, since this age group traditionally had the full-time occupation of college student. The nontraditional adult students, ages 25 and over, were the adults who worked full-time and were engaged in college part time. Traditional adult students might find a need for more directed instruction, as opposed to nontraditional adult students who would be more self-directed and require a different approach to instruction.

Efforts to assist nontraditional adult students in college and industry have been developed in recent years. The dominant trend in this training was to remove participants from the natural work/class environment and have them attend a seminar or workshop, then they would return to the original setting with new skills to use to assure a new success. Some practitioners in the field have mentioned an identified problem with many adult students' 
inability to transfer skills from one setting to another. Dr. Van Der Meij and other experts have argued that learning should take place within the environment and include discussions that involve exploration of background assumptions. Dr. Weinstein has developed intensive workshops for educating faculty on how to teach learning strategies and study skills, and she has further developed courses for incoming freshman for the purpose of learning how to learn.

There were a number of successful intervention activities at the high school level where study skills manuals were used by faculty during selected course curriculum to integrate study skills. The information was designed to be integrative as well as sequential in grades nine through twelve. Disadvantages were that there was not a quantitative means for evaluating the success of the program; although, the corporation which developed the manual is presently working on the further development of such an instrument (Shirley, personal communication, September, 1991).

Dr. Claude olney made strides in helping college students with his seminar and video called "Where There's A Will There's An 'A'." The seminar was developed out of a need to assist his son and other young adults in college who were experiencing academic difficulty. The success of his program was measured by the increase in the seminar 
participants' GPAs. The video of the seminar was selected to be used as the study skills program in this study. The Learning and study Strategies Inventory (IASSI) developed by Dr. Claire Weinstein and Associates, was used as the quantitative measurement in this study. The inventory was carefully developed, was judged to have content validity by expert judges, and had a test-retest reliability correlation coefficient of .88 for the total test. As Mealey (1988) pointed out however, there was concern over norming, as the pilot tests were run on limited samples, and recent data from the IASSI's widespread use has not been fully documented. 
CHAPTER III

\section{RESEARCH DESIGN AND METHODOLOGY}

\section{Introduction}

Three intact groups were used in this quasi experimental design. The researcher analyzed quantitative data collected from IASSI pretests and posttests and evaluated the impact of three methodologies of a study skills program built into course curriculum. A convenience sample was used and made the study quasi experimental, which brought with it threats to internal validity. The absence of pure random selection may bias results, a phenomena which was discussed in detail in chapter one under Assumptions and Limitations to the study.

The control group and two experimental groups were called intact groups because they were a convenience sample and lacked complete random assignment of the participants which made up the classes which in turn made up the intact groups. The Table of Random Numbers was used in assigning classes which were designated to the groups that became known as treatment group $A$, treatment group $B$ and the control group. 
Treatment group A was exposed to method A of the study skills program, treatment group $B$ was exposed to method $B$ and the control group which received no treatment was called method $c$.

Method A involved watching the study skills program without a manual on study skill techniques and without a group discussion led by the instructor immediately following the film. Method B involved watching the study skills program, referring to a manual on study skill techniques and participating in a group discussion about the video. Method $C$ had no treatment. Participants in all three groups took a pretest and posttest of The Learning and Study Strategies Inventory (LASSI).

The entire population of 101 participants was divided with 33 subjects in method A, 25 subjects in method $B$ and 43 subjects in method $c$. The subjects in each group were further subdivided into traditional and nontraditional students and the courses into business and nonbusiness classes (these terms were defined in Chapter One). All participants volunteered to take part in the study.

\section{Data Collection overview}

Two precursory steps were taken prior to the full scale study. A preliminary survey was administered to a convenience sample of community college and University of La Verne (ULV) Vandenberg Air Force Base and Naval Air Station 
North Island adult undergraduate students asking if they felt the need for such a study skills program. Next a pilot study was run with 18 adult undergraduate students enrolled in University of La Verne classes at Naval Air Station North Island. Finally a full study was conducted with adult undergraduates from Vandenberg Air Force Base and Naval Air Station North Island, who were enrolled in University of Ia Verne classes.

\section{Population}

A number of American-based universities offer liberal arts and business degrees to adult undergraduate students attending programs on military installations both here and abroad. The University of La Verne is one such school. The sample was drawn only from the University of La Verne, but it was hoped that inferences could be made about the overall population described above.

\section{Sample selection}

Introduction. The classes which were selected for both Vandenberg Air Force Base (VAFB) and Naval Air station North Island (NASNI) for the spring term, 1991, were placed on the schedule as a result of several factors: student needs, program requirements, and the normal cycle for particular classes to surface within the structure of the academic calender. A total of 17 classes $(9$ business and 8 
nonbusiness) began as scheduled with a total of 185 adult undergraduate students enrolled. Mortality, including lack of participation, was due to a number of perturbations which will be discussed under mortality in this chapter. Onehundred one adult undergraduates (22 traditional and 79 nontraditional) out of 111 volunteers completed the study. Students at the University of La Verne sites were assigned to classes according to their needs by the academic counselor and thus became a convenience sample of intact groups. Once the classes were established with their respective students, the Table of Random Numbers was used to assigned classes to groups A, B or C (Arkin \& Colton, 1963). After the first round of assignments, enrollment rosters were reviewed to see if there was a conflict in methodology for the students enrolled in the courses.

If this turned out to be the case, another round of random assignments was made. This process continued until only six students had conflicts. Students who were exposed to more than one methodology were removed from the data. only two students from the pilot, that ran during the winter, 1991 term and which was later pooled into the full study, turned out to be involved in the full study, and they too were removed from the data.

The rationale for pooling the pilot study with the main study was that: (a) Participants received identical treatment; (b) the same type of courses were offered for the 
pilot as in the full study; (c) identical procedures were used for instructors in the pilot as in the full study, (d) the students in the pilot were different from those in the full study with the exception of two students. The possibility of these two students affecting the study may be a weakness to the study, but is a small factor in 101 students overall.

The full study ran in the spring, 1991 term. All participants in all three groups were pre and posttested using the LASSI instrument. Attendance records were kept to identify subjects who viewed the study skills program. A and $B$ group students who were exposed to six out of eight study skill sessions were considered to have received the treatment. Six out of eight sessions was considered by faculty and staff involved in the project to be adequate. Control Group Method $c$. The control group had a total of 43 adult students. Thirty were in business classes and 13 were in nonbusiness classes. Eight were traditional adult students and 35 were nontraditional adult students. The protocol of group $C$ was to pretest and posttest the participants with the LASSI and to have no intervening treatment.

Treatment Group Method A. The first treatment group had a total of 33 adult students. Twenty-two were business and 11 were nonbusiness adult students. Five were traditional and 28 were nontraditional adult students. The 
protocol of group A was: (a) to pretest the participants with the IASSI; (b) to have students exposed to the study skill program without a manual or group discussion; (c) to posttest the participants with the LASSI.

Treatment Group Method B. The second treatment group had a total of 25 adult students. Fifteen were business and 10 were nonbusiness. Nine were traditional adult students and 16 were nontraditional adult students. The protocol of group B was: (a) to pretest the participants with the LASSI, (b) to expose participants to the study skill program with a manual on study skill techniques, (c) to have a group discussion which included challenging background assumptions on how to study in college, and (d) to posttest the participants with the LASSI.

\section{Instrumentation}

There were three instruments used in the study. The first was an opinionnaire divided into two parts designated for the preliminary survey. Part one asked adult postsecondary students if they would be interested in having an ongoing study skills program and part two listed nine items to be ranked according to interest and constituted an ipsative ranking (forced choice of the last item selected).

The second was The Learning and study Strategies Inventory (LASSI). One of the LASSI's functions was as a pre-post achievement measure for individuals who are 
participating in programs which involve study skills. The IASSI has 10 scales:

1. Attitude (ATT) - measures interest in college;

2. Motivation (MOT) - measures self-discipline toward study;

3. Time Management (TMT) - measures use of time for academic tasks;

4. Anxiety (ANX) - measures the degree the student worries about performance in school;

5. Concentration (CON) - measures ability to focus on academic tasks;

6. Information Processing (INP) - measures "imaginal and verbal elaboration" reasoning and comprehension;

7. Selecting Main Ideas (SMI) - measures the ability to pick up important information;

8. Study Aids (STA) - measures the use of support materials and techniques;

9. Self Testing (SFT) - measures preparation and reviewing methods; and,

10. Test strategies (TST) - measures the student's way of organizing material for examinations.

The IASSI pool of 72 items, which used a Likert-type scale, was assessed by expert judges on content validity. A test-retest reliability correlation coefficient of .88 was computed for the total instrument after the second pilot test. The pilot tests were run with adult students 
attending postsecondary educational institutions. Preliminary norms were set in 1982 when 850, who constituted the incoming freshman class at a small private liberal arts college on the east coast of the United states, participated in the study (Weinstein, 1987). Data on 780 were analyzed. Norms were further developed using 880 incoming freshman in a large southern university. User validity has been repeatedly tested. Scales have been validated against performance, validated by comparing scale scores to subscales which measure similar factors, and validated by feedback from counselors, educators and learning specialists who have reported high degrees of usefulness in their settings.

The third instrument was an exit survey which asked three things of participants: Constructive comments which would improve a study skills program, what the participant found to be most helpful, and what he/she found to be least helpful.

\section{Data Collection}

Data collection for the three tiers occurred as follows: The first tier of the study was to conduct a preliminary survey to evaluate whether there was an interest for a study skills program. This was a one-shot situation. During the fall semester, 1990, the preliminary survey consisting of an opinionnaire was given to a number of 
classroom instructors in local community colleges and at ULV programs at VAFB and NASNI. The respective classroom instructors distributed to and collected from a convenience sample of intact groups totaling 250 adult postsecondary students the opinionnaires and turned them over to the researcher for analysis. Two-hundred fifty opinionnaires were distributed and 250 were collected on the spot, which was a $100 \%$ return.

The second tier consisted of running a pilot study with a convenience sample of 18 adult undergraduates enrolled in classes through the University of Ia Verne at NASNI. The pilot ran for eight consecutive weeks during the winter term, 1991. The study skills program was shown once a week to the two experimental treatment method groups called A (a business course having one traditional and four nontraditional students), and B (a nonbusiness course having three traditional and three nontraditional students), and in which a manual of study skill techniques and a group discussion took place. There was no study skills program in the control group method C (a business course having no traditional and seven nontraditional students). Pre and post-IASSI tests were conducted, along with an exit survey, in all three groups by the respective instructors, then the LASSIs and surveys were turned over to the researcher for analysis. There were a total of 32 students registered in the three classes selected for the pilot study. Twenty-five 
volunteered to participate in the pilot and 18 of these 25 completed the study. The pilot's major function was to refine the administration of the study. The sample size (18 participants) and cell size (less than 10 subjects per cell) was too small to make confident evaluations or offer the possibility of replication.

The third tier consisted of running a full study at VAFB and NASNI involving undergraduate adult students enrolled in courses through the University of Ia Verne. one-hundred eighty-five students were registered and available to participate of which 111 volunteered (60\%). Of the 111 participants, 101 completed the study, which represented 91\%. The 101 participants were subdivided into control group method C ( 30 business, 2 traditional, 28 nontraditional\} \{13 nonbusiness, 6 traditional, 7 nontraditional $\})$ and treatment groups method A ( $\{22$ business, 2 traditional, 20 nontraditional\} \{11 nonbusiness, 3 traditional, 8 nontraditional $\})$ and B ( 115 business, 2 traditional, 13 nontraditional\} (10 nonbusiness, 7 traditional, 3 nontraditional\}). Respective course instructors administered the pre and post LASSI along with an exit survey and turned the instruments over to the researcher for analysis. 
Data Analysis

Descriptive and inferential statistics were used to formulate results for the preliminary survey, pilot and full study. Frequency distributions and means were used to analyze results of the opinionnaire from the preliminary survey. Multiple analyses of variance was used to analyze data from the LASSI: A 4-way MANOVA on student by class by Method by Time was used first since it was the minimum model needed to look at four variables. When both main effects and interaction effects involving student were insignificant, student was added to the error term, then two 3-Way MANOVAs on Location by Method by Time and class by Method by Time were run. Finally, one 2-way MaNova on Method by Time was run. Respective univariate $\underline{F}$ tests on the 10 LASSI scales which were the dependent variables and select Newman-Keuls post hoc comparisons were calculated. A qualitative exit survey was used by the researcher to identify faculty and student observations.

\section{Ethical Concerns}

The Committee for the Protection of Human Subjects reviewed the study in detail prior to giving approval for the research. Among the issues of concern were: Risk involved for participants, types of tests being used, purpose of data collection, informed consent of subjects, and risk/benefit ratio. 
once the study was underway, a couple of participants found that some of the questions from the inventory involved revelation of personal belief systems. It was important for the researcher to be sensitive to participants' needs and only those students who were willing to volunteer and sign consent forms were encouraged. Additionally, individual participant's privacy was assured through the use of numerical coding as an identifier.

\section{Mortality}

A variety of perturbations affected the number of participants who actually completed the study. The unexpected cancellation or change in classes from full class to directed study, the concern over possible involvement in operation Desert storm, the concern over a "non-military project," absenteeism, and missing LASSI pre or posttests contributed to mortality and absence of a larger number of volunteers completing the study.

The previous indications, based on three years of record review, of the independent variable student, with its two values of traditional and nontraditional, revealed a $60 / 40$ split favoring nontraditional students. This was the assumption upon entering the study; however, it proved not to be the case in both the pilot and full study. There was a noted absence of traditional students for some unknown reason. The limitation was placing the independent variable 
"student" into the error term and running the study without the highest order interaction. 


\section{CHAPTER FOUR}

\section{RESEARCH FINDINGS}

\section{Introduction}

The purpose of this study was to assess the efficacy of a study skills program built into the course curriculum of adult undergraduate students enrolled in classes through the University of La Verne (ULV) at Vandenberg Air Force Base (VAFB) and Naval Air Station North Island (NASNI). The project was divided into three parts, the first two being precursory: A preliminary survey, a pilot study and a full scale study. Data were collected respectively from a preliminary survey opinionnaire, and a IASSI pre and posttest along with an exit survey form. Data collected from these three parts were analyzed using a variety of techniques to describe the sample and make inferences about the population, to address the research questions, and to assess other areas of interest regarding study skills programs.

\section{Sample Description}

The three parts of the overall study were referred to as tiers. The first tier was a convenience sample of 250 
nonmilitary and military adult students attending community colleges in the San Diego area and ULV programs at both VAFB and NASNI. All 250 participants were asked to complete a two part opinionnaire (Appendix A). Research findings are reported under results of preliminary survey.

The second tier was a pilot study run with a convenience sample of $18 \mathrm{ULV}$ adult undergraduate students. They were approximately evenly divided into two treatment groups called $A$ and $B$, and a control group called $C$. The three groups were further subdivided into subsets called type of student and type of class. Research findings are reported under results of the pilot study.

The actual participants completing the study numbered 101. There were several possible reasons for such a small sample. The following perturbations were: class cancellations, some subjects' reluctance to participate out of concern over Desert Storm, a general disinclination on the part of some military personnel to participate in a nonmilitary volunteer program, and other mortality phenomena occurring from missing pre or post-IASSI tests. An exit survey was added to the design for this group. Since the study took place on two military installations, it was interesting to note, that during a time of war and economic uncertainty, active duty military personnel were uneasy regarding participation in this study. 
Subjects' stress levels may have impacted some of the findings. Findings are reported under significant Findings and Further Findings.

A multiple classification analysis of variance (MANOVA) was used to evaluate the data. The first approach used a 4way design since it was the minimum needed to look at the following variables which were of interest to the researcher: student, Class, Method, and Time. The assumption which accompanied this design was a minimum of 10 subjects per cell. The 4-way model did not meet the minimum subjects per cell, so it was run again without highest order interaction. Subsets within this model were analyzed. Next two 3-way and one 2-way MANOVAs were run, for cell sizes in these designs met or exceeded the minimum cell size requirement. However, the cells were of disproportionate size. To accommodate this phenomena, the MANOVA program contained within the software package produced by SPSSX (1987) was used.

This program was written based on an internal multiple regression analysis which adjusted for disproportionate cell sizes. The beta weights in the MANOVA were automaticaIIy translated into the language of analysis of variance and means. 
Seventy-four percent of the 250 participants polled said yes on part one of the opinionnaire that they would like a study skills program built into course curriculum (Table 1). A $95 \%$ confidence interval was built and it was calculated that the true proportion lay between .64 and .86 .

Table 1

Frequency counts on Part I of opinionnaire

\begin{tabular}{|c|c|c|}
\hline Program & Cases & of Total \\
\hline Yes & 186 & 74.40 \\
\hline No & 64 & 25.60 \\
\hline Total & 250 & 100.00 \\
\hline
\end{tabular}

Part two asked each participant to rank order highest to lowest interest in nine listed items to be included in a study skills program. Table 2 shows the relationship between the 9 items on the opinionnaire and the 10 IASSI attributes.

of the original 250 sample, 158 participants correctly completed part two. Grand means and their standard 
Table 2

Relationship of 9 Items on Opinionnaire to 10 LASSI Scales

\begin{tabular}{|c|c|c|}
\hline Item & $\begin{array}{l}\text { Code for } \\
\text { Preliminary } \\
\text { Survey }\end{array}$ & LASSI scale \\
\hline $\begin{array}{l}\text { How to prepare } \\
\text { for and review for } \\
\text { class }\end{array}$ & Review & SFT (Self-testing) \\
\hline $\begin{array}{l}\text { How to utilize } \\
\text { support materials }\end{array}$ & Support & STA (Support aids) \\
\hline $\begin{array}{l}\text { How to prepare } \\
\text { for and take tests }\end{array}$ & Test & TST (Test-taking) \\
\hline $\begin{array}{l}\text { How to increase } \\
\text { concentration }\end{array}$ & Think & CON (Concentration) \\
\hline $\begin{array}{l}\text { How to identify } \\
\text { main ideas }\end{array}$ & Idea & $\begin{array}{l}\text { SMI (Selecting main } \\
\text { ideas) }\end{array}$ \\
\hline & & $\begin{array}{l}\text { INP (Information } \\
\text { Processing) }\end{array}$ \\
\hline $\begin{array}{l}\text { How to increase } \\
\text { self-confidence } \\
\text { in academic } \\
\text { performance }\end{array}$ & Anxiety & ANX (Anxiety) \\
\hline $\begin{array}{l}\text { How to better } \\
\text { manage time }\end{array}$ & Time & $\begin{array}{l}\text { TMT (Time } \\
\text { management) }\end{array}$ \\
\hline $\begin{array}{l}\text { How to be self- } \\
\text { motivating }\end{array}$ & Motivate & MOT (Motivation) \\
\hline $\begin{array}{l}\text { How to develop a } \\
\text { positive attitude }\end{array}$ & Attitude & ATT (Attitude) \\
\hline
\end{tabular}


deviations (from most [1] to least [9] interest) are displayed in Table 3.

Table 3

Grand Means and Their Standard Deviations for Part II of opinionnaire

MEAN SD N

\begin{tabular}{llll} 
Test & 3.71 & 2.46 & $158 *$ \\
Think & 4.50 & 2.33 & \\
Review & 4.61 & 2.55 \\
Time & 4.81 & 2.63 & 2.37 \\
Idea & 5.01 & 2.43 \\
Motivate & 5.33 & 2.91 \\
Attitude & 5.40 & 2.52 \\
Support & 5.68 & 2.33 \\
Anxiety & 5.96 & \\
\hline
\end{tabular}

Note: $\star \mathrm{N}=158$ for each item; Items Ranked from Highest (low mean) to Lowest (high mean) in Interest.

Although there was enough discrepancy to rank the nine items, only Test stood out dramatically from the others since the set of nine constituted an ipsative measure, which means that the last item was a forced choice and results were not as objective as a likert type scale would have been. Results of the data analysis still indicated 
sufficient interest to develop the study skills program built into course curriculum, and results offered an indication that, of the total sample size selected, possibly about $70 \%$ might volunteer for the study.

\section{Results of the pilot study}

The primary function of the pilot was to smooth out procedures for conducting the full scale study. This included working with a complex model and interpreting the data which were derived.

A 4-way MANOVA design was used to calculate main effects on four independent variables: Method, class, Student and Time. The 10 dependent variables were the 10 scales of the IASSI. The procedure was to calculate the value of $\mathrm{p}$ and if none of the values were below .05 (alpha), no further investigation would take place. None of the findings was significant (Table 4 ).

since none of the findings was significant and the pilot groups were very small, the individuals from the pilot were pooled into the full study. Two individuals from the winter term (1991) pilot study who were registered again in the spring term (1991) were excluded from data collection. It was acceptable to pool the pilot with the main study for the following reasons: 
Table 4

Wilks' Lambda for the Pilot study

\begin{tabular}{lcc}
\hline Subject Variable & Wilks' Lambda Value & $\begin{array}{c}\text { Sig of } \underline{\underline{F}} \\
(\underline{\underline{p}})\end{array}$ \\
\hline Between Subject Effects & & \\
Method & .1642 & .257 \\
Class & .4692 & .859 \\
Student & .1667 & .263 \\
\hline Within Subject Effects & .1307 & .179 \\
Method by Time & .1660 & .262 \\
Class by Time & .6188 & .967 \\
Student by Time & .1922 & .325 \\
Time & & \\
\hline
\end{tabular}

Note: AII $\mathrm{p}>.05$, thus no significant difference Method, Class, student, and Time.

1. The individuals in both studies received the exact treatment,

2. The instructors in both studies received the exact instructions, and

3. The types of classes (business and nonbusiness) and types of students (traditional and nontraditional) were the same in both studies. 
Significant Findings

Significant findings were found for quantitative questions \#1, 3, and 5 (see Tables 5,6 , and 10). Qualitative questions \#6, 7, and 8 also revealed important information.

The 4-way MANOVA (without highest order interaction) Student By Class By Method By Time: Wilks' Lambda for (Full study) shows the initial significant findings to the quantitative research questions.

Research Question $\$ 1$ : Is there a difference among changes in LAssI means for the three presentation methodologies by time?

Time was found to be significant. Two 3-way MANOVAs and a 2-way MANOVA were run. Method by Time was significant in the first 3-way MANOVA Location By Method By Time (Table 6) as well as in the 2-way MaNOVA Method By Time.

The 3-way MANOVA that looked at Location by Method by Time showed: Within-subject effect of Location by Time had Wilks' Lambda equal to .8020 on 20 and 172 df which translated to a $\mathrm{g}$ value of .031 , which was clearly significant. This is not discussed in the text however, because we already know from between subject effect that location in and of itself is significant, the two locations differed innately at the beginning of the study, so it 
Table 5

Wilks' Lambda for (Full study)

4-Way MANOVA without Highest order Interaction.

Independent variables are Student, Class, Method and Time

\begin{tabular}{|c|c|c|c|}
\hline Subject Variable & $\begin{array}{l}\text { Wilks' } \\
\text { Lambda } \\
\text { Value }\end{array}$ & $\underset{\text { (p) }}{\operatorname{sig} \text { of }}$ & \\
\hline \multicolumn{4}{|c|}{ Between Subject Effect } \\
\hline student & .8075 & .056 & . \\
\hline Class & .8567 & .225 & \\
\hline Method & .8557 & .871 & \\
\hline student by class & .8722 & .322 & \\
\hline student by Method & .8265 & .711 & \\
\hline Class by Method & .9028 & .987 & \\
\hline $\begin{array}{l}\text { Within } \\
\text { Subject } \\
\text { Effect }\end{array}$ & & & $\begin{array}{l}\text { Reference } \\
\text { Research } \\
\text { Question }\end{array}$ \\
\hline Time & .7941 & $.036 *$ & None \\
\hline student by Time & .9355 & .848 & 2 \\
\hline Class by Time & .7866 & $.028 *$ & 3 \\
\hline Method by Time & .7871 & .445 & 1 \\
\hline $\begin{array}{l}\text { student by class } \\
\text { by time }\end{array}$ & .8904 & .463 & None \\
\hline $\begin{array}{l}\text { student by Method } \\
\text { by time }\end{array}$ & .8405 & .795 & 4 \\
\hline $\begin{array}{l}\text { Class by Method } \\
\text { by time }\end{array}$ & .6959 & .061 & 5 \\
\hline
\end{tabular}

Note: $* \underline{p}<.05$ 
Table 6

Wilks' Lambda for 3-Way MANOVA Location by Method by Time

\begin{tabular}{lcc}
\hline Subject Variable & $\begin{array}{c}\text { Wilks' } \\
\text { Lambda Value }\end{array}$ & $\begin{array}{c}\text { Sig of } \mathbf{F} \\
(\mathrm{D})\end{array}$ \\
\hline Between Subject Effect & .8018 & .460 \\
Method & .7949 & $.024 *$ \\
Location & .8397 & .663 \\
Location by Method & .8020 & $.031 *$ \\
Within Subject Effect & .6541 & $.008 *$ \\
Location by Time & .7515 & .171 \\
Method by Time & Location by Method by Time & \\
\hline
\end{tabular}

Note: $* \underline{p}<.05$.

followed that they would differ by location over time. Method by Time Wilks Lambda was equal to .6541 on 20 and 172 df which translated to a $\mathrm{g}$ value of .008 .

Univariate $E$ tests were run on the 10 dependent variables (Table 7). Four dependent variables came out with significant $\mathfrak{Q}$ values. Time Management (TMT) had a $\mathfrak{Q}$ value of .021, Information Processing (INP) had a $p$ value of .029 , use of support Aids (STA) had a p value of .015 Self-Testing and Reviewing for class (SFT) had a $\mathrm{p}$ value of .004. 
Table 7

Univariate F Tests. 3-Way MANOVA Location by Method by Time Effect: Method by Time

\begin{tabular}{lc}
$\begin{array}{l}\text { Dependent } \\
\text { Variable } \\
\text { LASSI Attribute }\end{array}$ & $\begin{array}{c}\text { Sig of } \mathrm{E} \\
(\mathrm{D})\end{array}$ \\
\hline Attitude & .482 \\
Motivation & .415 \\
Time Management & $.021 *$ \\
Anxiety & .491 \\
Concentration & .791 \\
Information Processing & $.029 *$ \\
Selecting Main Ideas & .888 \\
Use of Support Aids & $.015 *$ \\
Self Testing & $.004 *$ \\
Test Taking Strategies & .215
\end{tabular}

Note: $* \underline{p}<.05$

Time yanagement (TMT) (Appendix K) showed Control Group Method C at a LASSI pre mean of 27.67 SD 6.88 and post mean of 27.12 SD 6.54. Treatment Group Method A had a IASSI pre mean of 24.55 SD 5.20 and post mean of 26.73 SD 4.48 and finally, Treatment Group Method $\underline{B}$ with a IASSI pre mean 24.52 SD 5.58 and post mean of 26.04 with the same SD of 5.58. The $C$ group decreased by -.55 , the $A$ group improved by 2.18 and the $B$ group improved by 1.52 over time. Newman- 
Keuls post hoc procedure calculated that method $A$ was significantly different from method $C$, but that method $B$ did not differ from either $A$ or $C$ (Table 8 ).

The indication under Method by Time is that the students in the control group decreased in managing their time, but those students in either of the two treatment groups improved and that those in treatment method A (which was the videotape lesson without a manual and without group discussion) improved the most in time management as the semester progressed (3-Way MANOVA Location by Method by Time: Effect: Method by Time). Thus we might infer that when it comes to Time Management, Method A would be quick and beneficial for the overall population, as opposed to doing nothing at all.

Information Processing, in the 3-way MANOVA Location by Method by Time: Effect: Method by Time. Control Group Method $\subseteq$ had a pre-LASSI mean of 29.30 SD 5.23 and post mean of 28.65 SD 5.19. Treatment Group Method A had a pre-IASSI mean of 26.85 SD 5.87 and a post mean of 28.52 SD 5.77 . Treatment Group Method B had pre IASSI mean of 28.12 SD 6.06 and post mean of 30.00 SD 4.63 . In summary, those students in the Control Group Method $C$ decreased by -.65 , whereas those students in Treatment Group Method A improved by 1.67 , and the students in Treatment Group Method B improved the most by 1.88. Post hoc Newman-keuls showed that Method $A$ was significantly different from Method $C$, but Method $B$ was 
not significantly different from Method $c$, because of the size of the group in Method B. If one were to look only at mean and SD, one would intuitively select Method B as significantly different from Method c. However, the calculation of Newman-Keuls also looks at group size (Table 8). Inference may suggest that the population overall would benefit from the exposure of a method A type of study skills program on improving in the area of processing information. support Aids (STA) A LASSI pre mean of 26.30 SD 5.73 and post mean of 25.91 SD 5.10 for the Control Group Method c. Treatment Group Method had LASSI pre mean of 24.33 SD 5.00 and post mean 25.45 SD 5.66 , whereas Treatment Group Method B had a IASSI pre mean of 23.92 SD 6.65 and post mean of 26.80 SD 4.98. The Treatment Group Method $\underline{C}$ decreased by -.39, whereas Treatment Group Method improved by 1.12 and Treatment Group Method B improved the most by 2.88 . NewmanKeuls showed that Method B was significantly different from the control group, but that Methods $A$ and $C$ are not that different from one another on this measure. Thus, it could be inferred that the population overall may benefit most in learning to use support aids by participating in a Method $B$ type of study skills program.

The last dependent variable in this 3-Way MANOVA showing significance was self-Testing (SFT). Under Method by Time, Self-testing had a LASSI pre mean of 27.72 SD 5.27 for Control Group Method $\subseteq$, and a post mean of 26.47 SD 
5.44. Treatment Group Method A had a LASSI pre mean of 25.27 SD 5.16 and a post mean of 27.00 SD 5.29 , whereas Treatment Group Method B had a IASSI pre mean of 25.92 SD 6.44 and a post mean of 28.40 SD 4.31 . The control group $\subseteq$ decreased by -1.25 , Treatment Group Method A improved by 1.73, and Treatment Group Method B improved the most by 2.48. Newman-Keuls procedure showed both treatment groups $\underline{A}$ and $\underline{B}$ significantly different from the control group. This meant that over time those students who received some kind of treatment showed improvement in their self-perceptions of how they tested themselves and reviewed in preparation for class. It could be inferred that the overall population could benefit by exposure to either Method $A$ or $B$ in acquiring self-testing skills.

Summarizing 3-Way MANOVA Location by Method by Time: Effect Method by Time (Table 8), it could be expected Methods A or B would be most effective across the board for the population at large in learning Time Management (TMT), Information Processing (INP), use of Support Aids (STA), and acquiring self-testing strategies (SFT).

The 2-Way MANOVA Method by Time calculated the identical four dependent variables as significant: Time Management, Information Processing, Study Aids and SelfTesting. Another significant finding was made in response to research question 3 . 
Table 8

Newman-Keuls Post Hoc Comparisons (of Pre/Post Test

Differences) of Methods $C, B$, and A on Participants' IASSI

Attributes 3-Way MANOVA: Location by Method by Time, Effect: Method by Time

\begin{tabular}{|c|c|c|c|c|c|}
\hline $\begin{array}{l}\text { LASSI } \\
\text { Attribute }\end{array}$ & $\begin{array}{l}\text { GRP } \\
\text { SIZE }\end{array}$ & $\begin{array}{r}C \\
43\end{array}$ & $\begin{array}{c}\text { Methoc } \\
\text { A } \\
33\end{array}$ & $\begin{array}{r}B \\
25\end{array}$ & $\begin{array}{l}\text { Significant Difference } \\
\text { of One Group From } \\
\text { Another }\end{array}$ \\
\hline $\begin{array}{l}\text { Time Managew } \\
\text { Mean Change } \\
\text { SD }\end{array}$ & ment & $\begin{array}{l}-.55 \\
5.17\end{array}$ & $\begin{array}{l}2.18 \\
4.93\end{array}$ & $\begin{array}{l}1.52 \\
4.52\end{array}$ & $\begin{array}{l}\text { A significantly } \\
\text { different from } c\end{array}$ \\
\hline $\begin{array}{l}\text { Information } \\
\text { Mean Change } \\
\text { SD }\end{array}$ & $e^{\text {Proce }}$ & $\begin{array}{l}\text { essing } \\
-.65 \\
4.05\end{array}$ & $\begin{array}{l}1.67 \\
5.20\end{array}$ & $\begin{array}{l}1.88 \\
4.50\end{array}$ & $\begin{array}{l}\text { A significantly } \\
\text { different from } c\end{array}$ \\
\hline $\begin{array}{l}\text { Support Aids } \\
\text { Mean Change } \\
\text { SD }\end{array}$ & & $\begin{array}{l}-.39 \\
3.40\end{array}$ & $\begin{array}{l}1.12 \\
4.97\end{array}$ & $\begin{array}{l}2.88 \\
6.35\end{array}$ & $\begin{array}{l}\text { B significantly } \\
\text { different from C }\end{array}$ \\
\hline $\begin{array}{l}\text { Self-Testing } \\
\text { Mean Change } \\
\text { SD }\end{array}$ & & $\begin{array}{r}-1.25 \\
4.37\end{array}$ & $\begin{array}{l}1.13 \\
4.38\end{array}$ & $\begin{array}{l}2.48 \\
4.65\end{array}$ & $\begin{array}{l}\text { A,B significantly } \\
\text { different from C }\end{array}$ \\
\hline
\end{tabular}

Research question \#3. Is there a difference in change in IAS8I means between business and nonbusiness classes by time?

Within-subject effects of class by Time in the 4-way MANOVA had a Wilks-Lambda equal to .7866 on 10 and 80 df which translated to a $p$ of .028 . There was a significant difference. Univariate $\underline{F}$ tests were made on each of the 10 dependent variables (Table 9). Under Class by Time, Time 
Management (TMT) with a $\mathrm{p}$ value of .001 was found to be significant. Business students had LASSI pre mean 25.93 SD 5.94 and LASSI post mean 27.61 SD 5.51 compared to nonbusiness students who had LASSI pre mean $25.76 \mathrm{SD} 6.78$ and LASSI post mean 24.97 SD 5.63 (Appendix J) .

Table 9

Univariate $F$ Tests. 4-Way MANOVA Without Highest

Interaction Effect: Class by Time

\section{IASSI}

Attribute

Dependent

Variable

Attitude

Motivation

Time Management

Anxiety

Concentration

Information Processing

Selecting Main Ideas

Use of Support Aids

Self Testing

Test Taking strategies
Sig of $\underline{E}$

(D)

.638

.054

$.001 *$

.638

.269

.107

.727

.061

.081

.468

Note: ${ }^{*} \underline{p}<.05$ 
Business students improved by 1.68 and nonbusiness students decreased -.79. Because of the extremely small $p$ value under Time Management (TMT) at .001, the researcher felt confident that in the overall population business students would show improvement in their academic selfconcept of how they managed their time during the spring, 1991 semester. Since time management was not covered in any of the business courses or nonbusiness courses which ran during the winter and spring 1991 semesters, it could be inferred that the population may also show that students in business classes would show an improvement in how they manage their time during their academic career. significance was again found in research question 5.

Research Question \$5: Is there a change in LAssI means between method and type of class over time?

Since Effect, Class by Method by Time in the 4-way MANOVA (student by Method by class by Time), indicated a trend toward significance $(.061)$ a second 3-Way MANOVA was run with class by Method by Time as independent variables (Table 10).

Within-subject effect Time had a Wilks' Lambda equal to .7247 on 20 and 172 df which translated to a $\mathrm{p}$ value of .001 , which was highly significant. Univariate $\underline{\underline{F}}$ tests (Table 11) were run on the ten dependent variables and Attitude (ATT) was found to be significant at .027 . 
Table 10

Wilks' Lambda for 3-Way MANOVA Class, by Method by Time

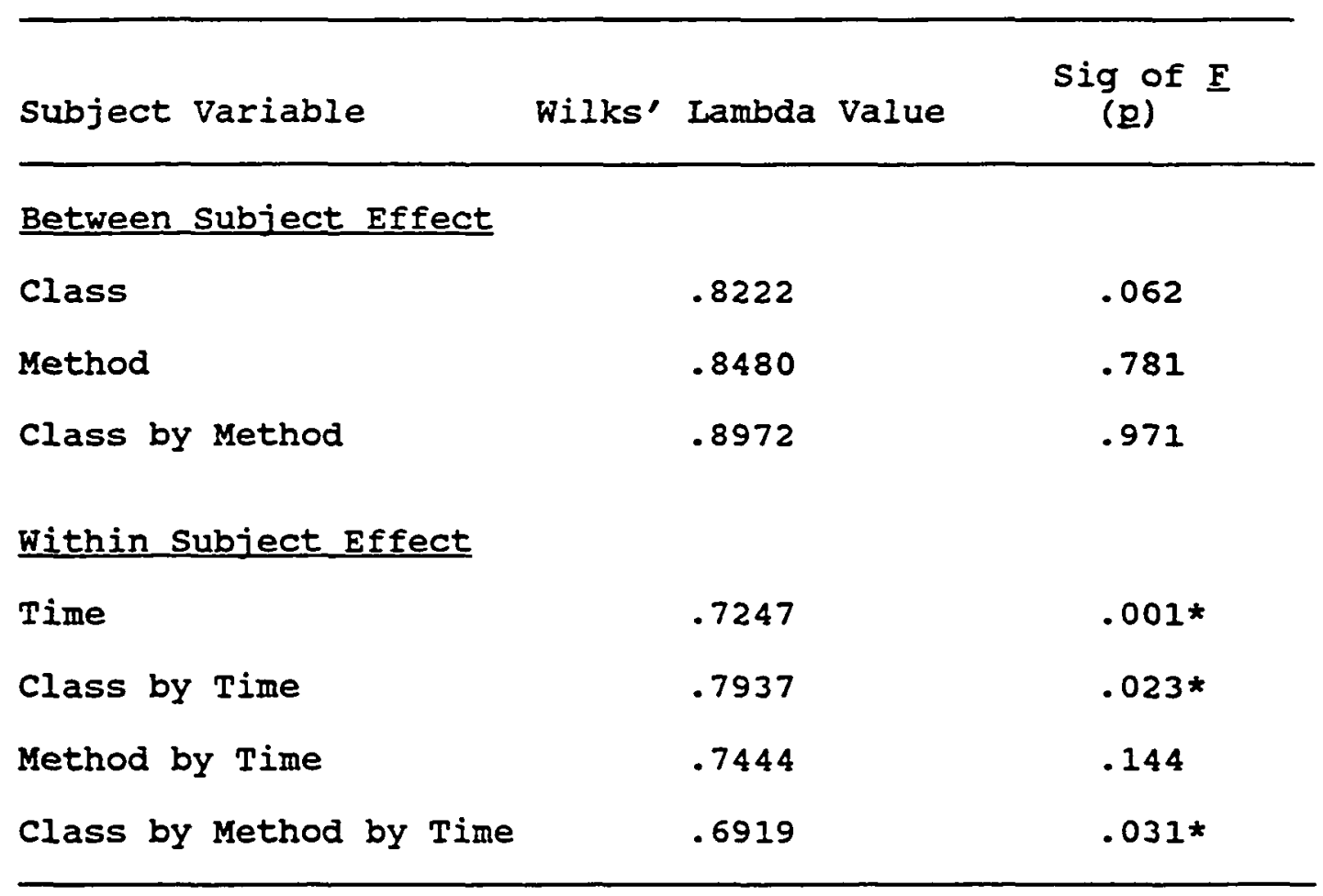

$\star \mathrm{p}<.05$

Attitude (ATT) for the entire sample had a LASSI pre mean 34.40 SD 3.78 and post mean of 33.40 SD 4.24 , which was a difference of -1.00 (Appendix J). Attitude for the entire sample decreased over time. Because of the high significance of Time as an independent variable (.001) in this 3-Way MANOVA, it could be inferred that the population overall might tend to develop a less positive attitude over time. This might suggest that a study skills program of shorter duration may be more beneficial on the attribute of attitude. 
Table 11

Univariate $F$ Tests for 3-Way MANOVA Class by Method by Time Effect: Time

Dependent

Variable

Sig of $\underline{F}$

(p)

Attitude

$.027 *$

Motivation

.057

Time Management

.207

Anxiety

.271

Concentration

1.000

Information Processing

.114

Selecting Main Ideas

.470

Use of Support Aids

.075

Self-Testing

.076

Test Taking strategies

.571

Note: $* \underline{p<.05}$

Within subject effect Class by Time had a Wilks' Lambda equal to .7937 on 20 and 172 df which translated to a 2 value of .023 and shows significance. Univariate $\mathrm{F}$ tests were made for the ten dependent variables (Table 12). Five were shown to be significant. Earlier, under the 4-WAY MANOVA, Effect Class by Time, only Time Management was significant. With this 3-Way MANOVA, four additional variables were significant (Appendix J). 
Table 12

Univariate $F$ Tests in 3-Way MANOVA Class by Method by Time

Effect: Class by Time

\section{LASSI}

Attribute

Dependent

Variable

Sig of $\underline{F}$

(D)

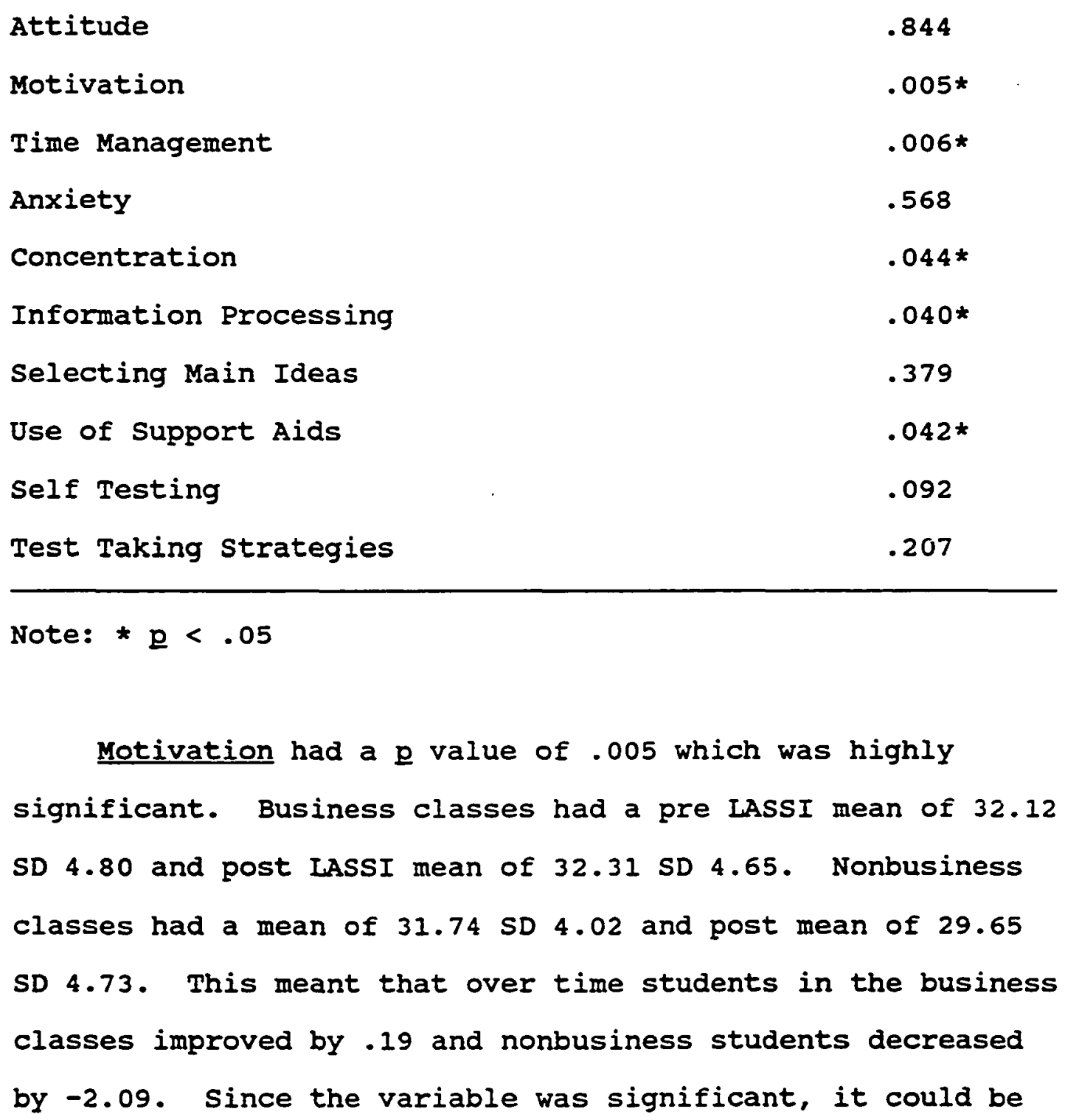


inferred that the overall population of business students may become more motivated as time passes, and the nonbusiness students could become less motivated over time. Concentration had a $\mathrm{p}$ value of .044 . Business classes had a pre LASSI mean of 29.51 SD 4.51 and LASSI post mean of 30.06 SD 4.53, whereas nonbusiness classes had a LASSI pre mean of 27.24 SD 5.76 and IASSI post mean of 26.44 SD 5.92 . This meant that over time business classes improved by .55 and nonbusiness classes decreased by -.79 . It could be inferred that for the overall population, students in business classes may improve concentration over time, and nonbusiness students may not concentrate as well over time.

Information Processing had a $\mathrm{p}$ value of .040 . Business classes had a LASSI pre mean of 28.24 SD 5.87 and post LASSI mean of 29.43 SD 5.21 and nonbusiness classes had a LASSI pre mean of 28.15 SD 5.43 and LASSI post mean of 27.29 SD 5.25. This meant that students in business classes improved over time by 1.19 and students in nonbusiness classes decreased by -.86 . It could be inferred that for the population at large, students in business classes may improve in information processing over time and nonbusiness students may decrease in information processing over time. Support Aids had a $\mathrm{p}$ value of .042. Business classes had a LASSI pre mean of 24.91 SD 5.72 and a LASSI post mean of $26.36 \mathrm{SD} 5.53$, and nonbusiness students had a IASSI pre mean of 25.38 SD 6.01 and LASSI post mean of 25.24 SD 4.58 
Business classes improved by 1.45 and nonbusiness classes decreased by $a-.15$. The inference was that over time students in business classes improve in their use of support aids and nonbusiness students decrease slightly.

The overall pattern of inference was that over time, by and large, the population of business students will improve over time in their motivation, time management, concentration, information processing and use of support aids, above and beyond their nonbusiness counterparts (Table 13).

The last effect looked at in the second 3-Way MANOVA was Class by Method by Time. The effect had a Wilks' Lambda of .6919 on 20 and $172 \mathrm{df}$ which translated to a value of .031 . Univariate $\underline{F}$ tests on the 10 dependent variables showed four to be significant (Table 14). Anxiety (ANX) had a $\mathrm{p}$ value of .050 , Concentration (CON) had a p value of .005 , Information Processing (INP) had a $p$ value of .021 , and self-testing and reviewing for class (SFT) had a g value of .039 .

The first of the significant dependent variables which was ngxiety (ANX) had the following means and standara deviations for Class by Method by Time (Appendix M) : Control group $C$ business had pre mean 28.87 SD 7.28 , post mean 28.77 SD 7.18; nonbusiness pre mean 25.62 SD 7.33 and post mean 28.15 SD 6.88 . Business students in the control 
Table 13

Change in Significant LASSI Attributes (Pre/Post Test

Differences) of Classes Business and Nonbusiness

3-Way MANOVA: Class by Method by Time, Effect: class by Time

LASSI

Attribute

Type of Class

$\begin{array}{cc}\text { Business } & \text { Nonbusiness } \\ \text { class Size } 67 & 34\end{array}$

Time Management

Change Mean

SD

Motivation

Change Mean

SD

Concentration

Change Mean

SD

INP

Change Mean

$S D$

$\underline{\text { STA }}$

Change Mean

SD
1.69

$-.79$

5.35

3.98
.19

$-2.09$

4.46

3.65
$-.79$

4.79

4.02 
Table 14

Univariate $F$ Tests on 3-Way MANOVA Class by Method by Time

IASSI

Attribute

Dependent

Variable

Sig of $F$

(D)

Attitude

.925

Motivation

.267

Time Management

.270

Anxiety

$.050 *$

Concentration

$.005 *$

Information Processing

$.021 *$

Selecting Main Ideas

.088

Use of Support Aids

.157

Self Testing

$.039 *$

Test Taking strategies

.068

Note: $* \mathrm{p}<.05$.

group decreased over time by -.10 . Nonbusiness students in the control group improved over time by 2.53 . Treatment group $A$ had business pre mean 28.82 SD 5.41 and post mean 30.59 SD 6.12 ; ; and nonbusiness pre mean of 29.27 SD 3.85 and post mean 29.00 SD 4.82 . Business students in treatment group A improved by 1.77 and nonbusiness students decreased by -.27 . Treatment group B had business pre mean $27.73 \mathrm{SD}$ 5.80 and post mean 28.47 SD 6.37 ; and nonbusiness pre mean 
25.30 SD 4.95 and post mean $23.80 \mathrm{SD} 6.03$. Business

students in treatment group B improved by .73 and nonbusiness students decreased by -1.50 . Although post hoc Newman-Keuls (Table 15) showed that overall there was no significant difference among the three methodologies, business students improved with some kind of treatment and nonbusiness students did better without treatment.

The second significant dependent variable concentration (CON) had the following means and standard deviations for method by class by time: Control aroup $c$ business had pre mean 30.63 SD 4.94 and post mean 30.10 SD 3.63 ; nonbusiness had pre mean 27.00 SD 6.73 and post mean 27.69 SD 6.30 . Business students in the control group decreased by -.53 and nonbusiness students improved by .69 . Treatment group $A$ business had pre mean 29.55 SD 4.08 and post mean 29.82 SD 6.08; and nonbusiness had pre mean 27.64 SD 4.78 and post mean 27.27 SD 4.34. Business students in treatment group $A$ improved by .27 and nonbusiness students decreased by -.36 . Treatment group B business had pre mean 27.20 SD 3.45 and post mean 30.33 SD 3.70 ; and nonbusiness pre mean had 27.10 SD 5.97 and post mean 23.90 SD 6.67 . Business students in treatment group B improved by 3.13 and nonbusiness students decreased by -3.20 . Newman-Keuls procedure calculated that business students in Treatment Group $\underline{B}$ Business were significantly different from those in the Treatment Group B nonbusiness at the .05 alpha level. It can be inferred that 
for the population at large, students in business classes would improve with treatment B for concentration, and nonbusiness students would do best without treatment $B$. The third significant dependent variable Information processing (INP) had the following means for method by class by time: Control group $C$ business had pre mean 29.83 SD 5.32 and post mean 28.70 SD 5.35; and nonbusiness pre mean 28.08 SD 5.01 and post mean 28.54 SD 5.01. Business students decreased by -1.13 and nonbusiness students improved by .46 Treatment group business had pre mean 26.55 SD 6.05 and post mean 29.27 SD 5.65; nonbusiness had pre mean 27.45 SD 5.73 and post mean 27.00 SD 5.98 . Business students improved by 2.73 and nonbusiness students decreased by -.45 . Treatment group $B$ business had pre mean of 27.53 SD 6.20 and post mean 31.13 SD 4.07; and nonbusiness had pre mean 29.00 SD 6.06 and post mean 28.30 SD 5.10. Business students improved by 3.60 and nonbusiness students decreased by -.70 . Newman-Keuls procedure calculated that both treatment groups A and B Business were significantly different from control group $C$ Business at the .05 alpha level. Inference for the overall population is that students in business classes improve with a study skills treatment and nonbusiness students do better without treatment.

The last significant dependent variable in the 3-way MANOVA Class by Method by Time was self-testing (SFT). 
Table 15

Newman-Keuls Post Hoc Comparison of Pre/Post Test

Differences of Methods $C, B$, and $A$ by Classes Business and

Nonbusiness on Participants' IASSI Attributes. 3-Way MANOVA

by Time, Effect: Method by Class by Time.

Method \& Class

LASSI

Attribute

\begin{tabular}{|c|c|c|c|c|c|c|c|}
\hline \multirow{2}{*}{ Class } & & \multicolumn{4}{|c|}{ Method \& Class } & & \multirow{2}{*}{$\begin{array}{l}\text { Significant } \\
\text { difference of } \\
\text { one group } \\
\text { from another }\end{array}$} \\
\hline & $B *$ & $\mathrm{~B} *$ & B & B & B & B & \\
\hline size & 30 & 13 & 22 & 11 & 15 & 10 & \\
\hline
\end{tabular}

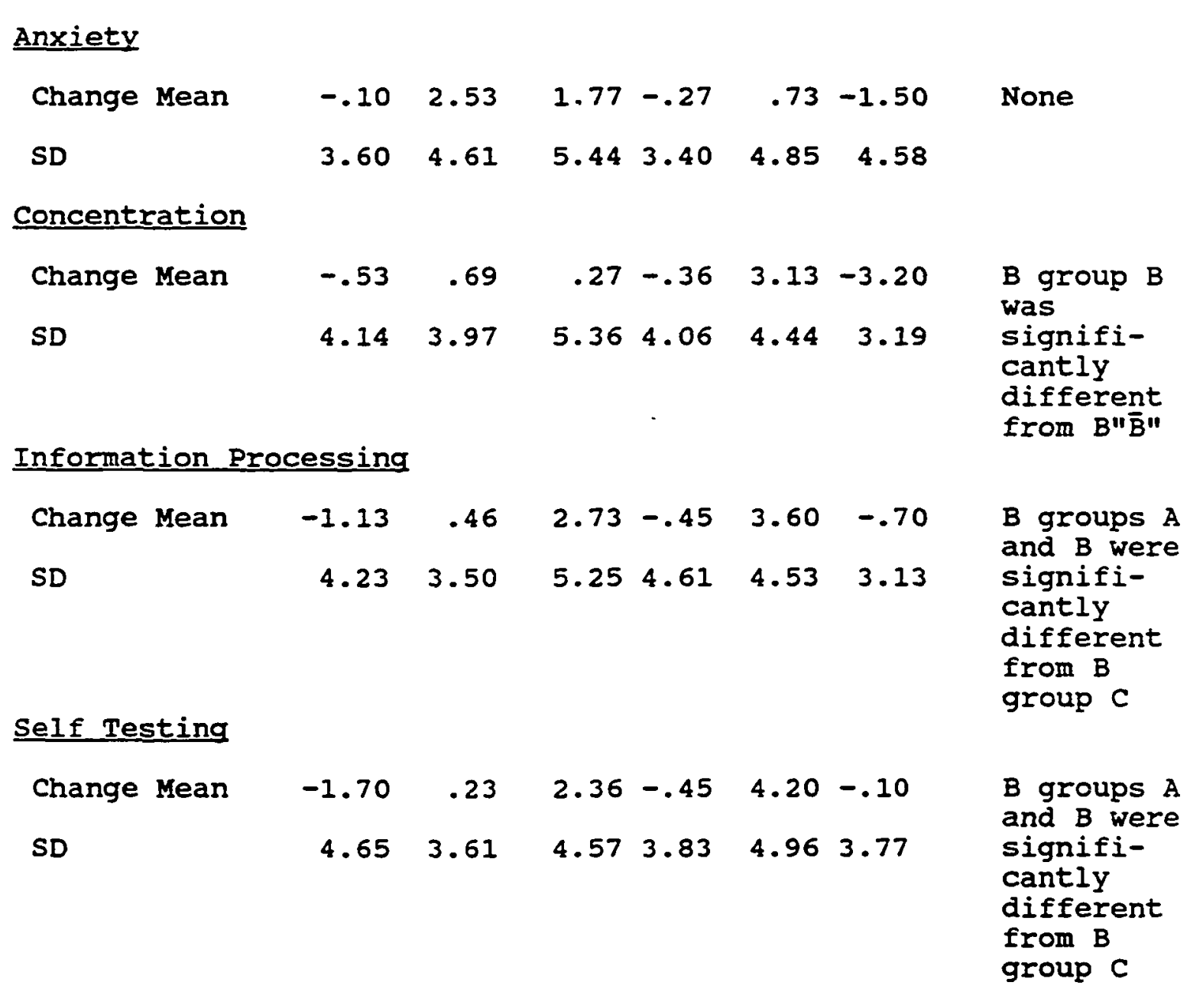

Note: $\quad \star B=$ Business Classes; $B=$ Nonbusiness classes 
Control Group C had business pre mean 27.63 SD 5.69 and post mean 25.93 SD 5.59 ; and nonbusiness pre mean 27.92 SD 4.33 and post mean 27.69 SD 5.07. Business students decreased by -1.70 and nonbusiness students improved by .23 . Treatment group A had business pre mean 25.18 SD 5.64 and post mean 27.55 SD 5.49: nonbusiness pre mean 25.45 SD 4.30 and post mean 25.91 SD 4.93. Business students in treatment group A improved by 2.36 and nonbusiness students decreased by -.45 . Treatment Group B had business pre mean 25.13 SD 6.46 and post mean 29.33 SD 4.10 ; and nonbusiness had pre mean 27.10 SD 6.56 and post mean 27.00 SD 4.45. Business students improved by 4.20 and nonbusiness students decreased by -.10 . Newman-Keuls procedure calculated that both treatment groups $A$ and B Business were significantly different from group C Business at the .05 alpha level. The inference is possible that the overall population of students in business classes will benefit from a study skills treatment and that nonbusiness students may do better without treatment. This concludes significant quantitative findings which will be discussed in chapter Five, along with qualitative findings which answer questions six through eight.

Research question $\$ 6$. Was there commonality among students on suggestions for improving an ongoing study skills program? (Research questions 6-8 reference Table 16 for student responses and Table 17 for faculty responses.) (Exit survey is Appendix I.) 
Evidence gathered from participants at both VAFB and NAS North Island suggested that a study skills program could be improved by having a dynamic speaker, high quality video taped sessions, and tailoring the sessions to the level of student. Eighteen student exit surveys were collected from VAFB, of which 6 were group B subjects and 12 were group A

Table 16

Exit Survey Patterns By Student Participants in Groups A and $B$

\begin{tabular}{|c|c|c|}
\hline $\begin{array}{l}\text { Sample } \\
48\end{array}$ & $\begin{array}{l}\text { Group A } \\
\text { VAFB } 12 \text { NASNI } 15\end{array}$ & VAFB 6 NASNI \\
\hline $\begin{array}{l}\text { Constructive } \\
\text { suggestions }\end{array}$ & $\begin{array}{l}\text { Students learn by doing. } \\
\text { stress course content. } \\
\text { Need more dynamic } \\
\text { speaker. Need more } \\
\text { visual aids. } \\
\text { Better quality video. }\end{array}$ & $\begin{array}{l}\text { Man on video needs } \\
\text { to talk faster. } \\
\text { Better presentation. }\end{array}$ \\
\hline Liked Most & $\begin{array}{l}\text { The many study skills. } \\
\text { The philosophy of } \\
\text { working smarter. }\end{array}$ & $\begin{array}{l}\text { The tips, they } \\
\text { seemed to have } \\
\text { worked. } \\
\text { Great group talk. }\end{array}$ \\
\hline & $\begin{array}{l}\text { Biological clock: } \\
\text { know yours. }\end{array}$ & $\begin{array}{l}\text { Sessions were short } \\
\text { enough. Study } \\
\text { techniques. } \\
\text { The manual. }\end{array}$ \\
\hline Liked Least & $\begin{array}{l}\text { The continuous reference } \\
\text { to success stories. } \\
\text { Film not appropriate to } \\
\text { level of education. }\end{array}$ & $\begin{array}{l}\text { (Video speaker) } \\
\text { monotone, refers } \\
\text { too much to sons. }\end{array}$ \\
\hline
\end{tabular}


Table 17

Exit Survey Patterns By Faculty Participants In Groups $A$ and $B$

\begin{tabular}{|c|c|c|}
\hline $\begin{array}{l}\text { Sample } \\
\text { Size } \\
6\end{array}$ & $\begin{array}{l}\text { Group } \\
\text { A } \\
I \text { North Island } 0\end{array}$ & $\begin{array}{l}\text { Group } \\
\text { B } \\
\text { NAS North Island } 3\end{array}$ \\
\hline $\begin{array}{l}\text { Constructive } \\
\text { Comments }\end{array}$ & $\begin{array}{l}\text { Course curriculum } \\
\text { is demanding - no } \\
\text { time to fit in } \\
\text { a study skilis } \\
\text { program. }\end{array}$ & $\begin{array}{l}\text { Relate program to level } \\
\text { of student. Program } \\
\text { should be experiential. } \\
\text { Treat all college like } \\
\text { your business career. }\end{array}$ \\
\hline Liked Most & Nothing! & $\begin{array}{l}\text { Study techniques good. } \\
\text { Learning how and what } \\
\text { to study and how to } \\
\text { take tests. The manual } \\
\text { and discussion were } \\
\text { good. }\end{array}$ \\
\hline Liked Least & Testimonials & $\begin{array}{l}\text { Quality of video tape. } \\
\text { Ideas on instructor \& } \\
\text { class selection. } \\
\text { style of the video. } \\
\text { Some of the speaker's } \\
\text { ideas, i.e.'do not } \\
\text { use underlining. }\end{array}$ \\
\hline
\end{tabular}

participants. All participants from VAFB were business majors in business classes and are marked with an asterisk. In response to how the study skills program could be improved, Group B subjects said:

* Presenter was boring - need either a more dynamic presenter or have classroom instructor present these techniques.

* A better quality of tape. The tape quality was hard to follow at different times.

* Improve quality of VCR/video 
* Better presentation - Better quality of film. I felt it was geared for high school level.

* Quality of film.

* (One student did not respond to the first question.) In Group A 12 subjects commented on how the study skills program could be improved as follows:

* Material presented in the video was sufficient.

* Study techniques were good, but could all have been done in 30 minutes total.

* Not having them.

* Enthusiasm.

* More lively!?

* Making it more interesting.

* Not showing them at the end of the class session.

* The material is very dry, and after 2 hours of lecture, many students fall asleep.

* Instructor should incorporate such skills into the lecture.

* More variety in lecture style.

* A different presenter.

* Eliminate the videos and have your own teacher present the ideas. The video picture was not that clear.

A total of 30 exit surveys were gathered from NAS North

Island students. Testimonials marked with an asterisk

indicate business majors in business classes. The 15 which were Group B participants had the following suggestions for improving the study skills program:

The speaker not talking in a monotone. He wasn't a very interesting speaker.

Having another speaker in the video. 
Having the man on the video talk faster.

* No improvement needed.

Better quality.

Better quality videos.

A little clearer video. Also not carrying the VCR up and down the stairs all of the time.

Get a better copy. Screen to see which would help out part time students like us.

Getting a better copy.

The quality of the tapes needs to be improved. Overall though, I found the sessions to be of short enough duration to where I would not lose interest.

* Showing cartoons!

* Having one change his voice and not being so monotone.

* (Three students did not respond to question 1.)

NAS North Island's 15 group A subjects gave their ideas on improving the study skills program:

speaker is too much on himself and his sons.

Setting aside a period of time to view it in one sitting.

More dynamic speaker.

No comment.

Cutting them out.

Better quality TV

Put the VCR downstairs!

With the true confession it looked/seemed like a cheap ad.

Making them an elective: if one wants to see the video, then they should be allowed. I felt the student testimonials were a bit overdone, and I found that I lost interest as a result. 
Filming a different instructor. He was very dry and slow. - Drove me nuts.

showing it to high school students.

Presentation methods, i.e., speaking more dynamic, visual aids.

Having a more fluent and vibrant speaker.

(Two students did not respond.)

There was commonality of view among students who filled out the exit survey on suggestions for improving the study skills program. Almost all students desired a more articulate and dynamic speaker. Students also desired a more easily accessible TV/VCR and better quality tapes. A few felt the tapes should be eliminated all together and a couple felt the material was presented at the high school level.

A total of six instructors completed the exit survey. Three from VAFB and three from NAS North Island. VAFB Group B teachers said:

* Relate the program to the group in the course. specifically, the students in my course were not at the same "level" as the students the tape was geared toward (i.e., my students were working adults, not high school senior or college freshman).

* Very little on the film was applicable to accounting degree students.

There was one Group A instructor from VAFB who responded:

* None. The demands of time on the classes I teach leave little spare time for a study skill program in my course.

NAS North Island also had three instructors, all of whom were Group B leaders. Business instructors are indicated with an asterisk. They commented the following: 
He did have a few good ideas - like teaching classes like a job.

* Students learn by doing. It's generally a waste of time to concentrate on (unable to read). Just (unclear), stress course content - tell students the benefits of knowing, etc.

* Good change of pace.

Faculty representatives expressed a variety of suggestions. There was concern for having a study skills program reflect the students level in school as well as course content. Another teacher was concerned with how to fit a study skills program into an already crowded curriculum. A third lecturer sought a more experiential learning experience for adult students. There was a general anxiety over developing the best type of program and then finding a way to successfully implement it.

\section{Research Question 7 . Was there commonality among} students in what they found to be most helpful?

Evidence suggested that both - a manual of study skill techniques and group discussions were beneficial to reinforcing study skills learned.

The six group B VAFB students found the following to be most helpful:

* The emphasis on neatness in homework materials, term paper, reviews, etc. The manual.

* Memorization techniques, study techniques.

* To read ahead before a class starts. Take notes on $3 \mathrm{X}$ 5 cards and study from them. Discussion.

* Great group interaction after film. 
* The many good techniques, I'm trying to use them in my other classes.

* (One student did not answer.)

The 12 Group A VAFB students offered the following ideas about what they found to be most helpful:

* There were many "tips" on studying that are common sense, but which I hadn't used before. I have found them useful.

* Study techniques.

* All that I found helpful could have been presented in a fifteen minute synopsis of study habit improvement.

* Helpful points to becoming a better student, which was the object of the video.

* The "study habits."

* None of it.

* None

* None

* Techniques.

* The many techniques.

* The study skills.

* (One student did not respond.)

The 15 Group B student subjects at NAS North Island

found the following to be most helpful:

The tips. I tired to incorporate some in my habits. They seem to have worked.

Part I - College is business - I wish it were not so business like.

The study hints helped me in this semester's classes.

* All parts.

Use an erasable pen on writing papers.

studying tips. 
Memory improvement. Tips and studying tips.

Using an erasable pen during a written exam, neatness will improve your grade.

The one (technique) which talks about studying in short bursts.

Erasable pens during essays.

Some of the most helpful areas had to do with learning techniques, i.e., sitting in the front row and asking questions.

* None!

* About the neatness of term papers, etc.

* Techniques to study by.

* I didn't find any of it very helpful.

* Take good notes.

The 15 Group A student participants at NAS North Island commented as follows:

study techniques.

Making an essay, receive a better grade by adding

little extras, garnishing.

Many of the techniques.

study habits - lots of media to study by.

None.

study techniques.

Biological clock - know yours!

Bits and pieces from all parts.

The basic philosophy of learning to study smarter, not harder is important. I felt excited in anticipation of learning new ways to make this philosophy work for me.

Some of the information presented.

None.

The many study skills. 
Some good general knowledge on study habits and tricks on earning a higher GPA.

None.

(One student did not respond.)

The many study skill techniques were helpful to the majority of students, who turned in exit surveys. There were a few who found none of the ideas helpful. Faculty Group B participants from VAFB found the following helpful:

* The booklet (manual) was the most helpful. It provided the study skill information in a quicker method, than watching the tape. Group discussions were excellent.

* The things that did apply were basically just common sense ideas on how and what to study in a course and how to take tests.

* The one group A VAFB instructor found "nothing!" helpful. The three group B instructors from NAS North Island offered the following advice regarding what was most helpful:

* Substance of the video

Good ideas, treating classes like a job.

* Bribes work! Just Kidding!

In summary, faculty representatives felt there were some good ideas in the video. Some felt it was also helpful to have a manual and discussion.

Research question \$8. Was there commonality among students in what they found to be least helpful?

Evidence suggested that the video was not appropriate to educational level. There were too many success stories. 
The video presenter was monotone and referred to often to his sons.

The six VAFB Group B students found the following least helpful:

* Baking a pie for the teacher, changing your name, the car you drive, etc.....

* Course selection strategies.

* The hints on changing your grade to an A. I feel that is degrading a person.

* The monotone voice of the video guy and too many "testimonials."

* (Two students did not respond.)

The 12 Group A VAFB students said:

* Nothing comes immediately to mind.

* Long winded discussions.

* Wasting time listening to twenty minutes of examples for 10 seconds of study hints.

* Monotone of presenter.

* The testimonials.

* Interfering with my regular class time.

* Most.

* Lack of variety in presentations.

* The lecturer on the video tape - not enough variety in presentations.

* I wish I knew about this earlier in my college career.

* (Two students did not respond.)

The 15 Group B students from NAS North Island

listed the following as liked least:

Anything learned could be helpful, even if it was only one tip. 
All parts were helpful!

I think this tape could be more on an adult level, and not as commercialized.

* All parts were somewhat helpful.

In all actuality, all parts present some type of helpful hints.

Sleeping patterns did not really help. Group discussions were great.

The last session concerning memory and study according to your biological clock. I don't think this is realistic.

The concept of having a "lucky pen" I found a bit farfetched.

* AlI!

* Always relating to his son... boring!

* Was the instructor's negating everything that the video said. I also feel that as a new student the intent of this "experiment" was not fully explained, it was assumed that all of the students knew. I also feel the event wasn't really voluntary, because it was done during class time, although I did volunteer.

* Make a pie for your professor!

(Three students did not respond, *one of whom was a business student.)

The 15 Group A students from NAS North Island found the following to be least helpful:

The information on his (the video presenter) son.

None

Same (Bits and pieces from all parts)

The videos were boring after awhile, because I felt the speaker was not presenting the information in a challenging, motivating manner. After a time I was tuning out. The presentation seemed long and monotonous.

Time spent watching it. 
All of it. It was not very appropriate for this level of education. If this film is going to be used in the future, I suggest that it be given to students prior to enrollment.

The continuous reference to success stories.

The person doing the presentation.

Not really that helpful.

No comment.

N/A

(Four students did not answer this question.)

In summation, students disliked the presenter's dry humor, and monotonous presentation style. students felt there were too many testimonials. One student was uncomfortable with the classroom instructor in the B group challenging material in the video.

The three instructors from VAFB found the following least helpful:

* The quality of the video tape was difficult to watch.

* The speaker's ideas of selecting classes and professors.

* The testimonials.

The three NAS North Island faculty offered their suggestions on the least helpful aspects:

* The speaker telling them that underlining and other (unclear) matters aren't a bit essential.

* Style of video.

Suggestions that instructors could be bribed - with a strawberry pie.

Instructors felt both the quality and style of video was not helpful. They also resented ideas focusing on class 
selection, and professor selection. The topic of bribing instructors appeared to be offensive.

\section{Further Findings}

There were a number of findings which lacked significance and are added because they either address a particular research question or explain the dismissal of a question for further scrutiny. Means tables, as for earlier discussion, are listed in the appendices.

The first research question posed the following issue: Was there a difference among changes in LASSI means for the three presentation methodologies by time? There were a number of significant findings in the 3-way and 2-way MANOVAS; however, no significance was found at the 4-way MANOVA calculation. Within-subject effects of Method by Time in this model had a Wilks' Lambda equal to .7871 on 20 and 160 df which translated to $\mathrm{g}$ of .445 . Thus, in the broad view, there was no external difference among the three presentation methodologies. Significant findings noted early on were found within each of the methodologies.

The second research question asked if there was a difference in change in IASSI means between traditional and nontraditional students over time. Some learning theory, such as Malcolm Knowles' views of the difference between pedagogy and andragogy, offers the possibility that differences indeed exist between the learning styles of children and young adults, and mid-career adults (which the 
researcher has differentiated as 18 to under 25, and over 25 respectively). The investigator's view led to research on the independent variable called student. Student was further subdivided into traditional and nontraditional (18 to under 25 and over 25). Unfortunately, there was an inadequate sample size to meet the minimum cell requirement on the MANOVA program and this variable was consequently abandoned. Thus, it remains unknown whether or not age makes a difference in response to the treatments prescribed within over a period of time.

The fourth research question was again associated with the independent variable student, and once again further investigation was terminated for the reasons stated in the above paragraph.

\section{Summary}

Prior to beginning the study two precursory steps were taken: A preliminary survey and a pilot study. The preliminary survey suggested enough interest on the part of undergraduate postsecondary adult students to pursue a study to see if a study skills program built into course curriculum might benefit such students.

A pilot study was established to refine the logistics of handling a larger study at two different sites served by the University of La Verne. The pilot ran at NAS North Island with 18 adult undergraduates somewhat equally divided into a control group and two treatment groups. A 4-way 
MANOVA was run on Student by Method By Class BY Time, for the sole purpose of identifying program "bugs" and making necessary adaptations for the full study. Since the sample size was so small, the study was insignificant in its findings, so the 18 participants from the pilot were added to the full study. This procedure was acceptable since the participants received the exact identical treatment, the instructors received the same training and the type of classes in which the students were enrolled was also the same. Only two students from the pilot were again enrolled in courses which ran during the full study. They were excluded from the study a second time. Any contamination from their interaction was considered minimal, since the sample size was 101.

The full study finalized with 101 total participants. It took place at VAFB and NAS North Island in undergraduate classes offered by the University of La Verne. One 4-WAY MANOVA on Student by Method by class by Time, two 3-WAY MANOVAs on class by Method by Time and on Location by Method by Time, and one 2-WAY MANOVA on Method by Time were run to address five quantitative research questions. The 4-WAY MANOVA revealed: (a) That there was a change in business and nonbusiness classes over time in how they managed their time in that business students improved and nonbusiness students decreased; and, (b) That there was a trend toward a difference between methodology and type of class over time. The 3-WAY MANOVA on Location by Method by Time showed that 
different methods had an impact over time on LASSI scales Time Management, Information Processing, Use of Support Aids and self-Testing. In summary all students in the control group decreased, all students in a treatment group got better and those in treatment group $B$ improved the most on Information Processing, Use of Support Aids and SelfTesting.

The 3-WAY MANOVA Class, by Method by Time showed significance on Anxiety, Concentration, Information Processing and self-testing over time. Nonbusiness students improved in the control group and decreased in either treatment group on all four scales. Business students improved in both treatment groups and decreased in the control group on these same scales.

Three qualitative questions were posed on an exit survey. In summary, constructive comments made by students who were in both treatment groups gave evidence suggesting that study skills programs be tailored to both type of class and student standing, e.g., freshman, sophomore, junior or senior. Most helpful were a manual condensing study skills techniques and group discussions relating to applications of the techniques to course content. Finally, that which was found to be least helpful was the quality of the video tape, the monotone of the presenter in the tape, testimonials and a lack of visual aids.

Conclusions in this limited study offer a number of suggestions. It appears that over a 10-week accelerated 
semester, nonbusiness adult students attending postsecondary colleges and universities on military installations do best when this type of study skills component is not built into course curriculum. Research findings further suggest that adult students attending colleges and universities on military installations and majoring in business improve over time when this kind of study skills program is built into course curriculum. Further, it is indicated that for some types of business students a study skills program is beneficial as long as it is concise and discussed by the classroom instructor in a dynamic and enthusiastic manner with an accompanying manual, which is the group B method. However, for the majority of business students, the group $A$ method proved most beneficial. This method was the brief presentation of a study technique, excluding manual or discussion. The inference to the population at large would be that the group A method would be beneficial to business students, rather than not having any type of study skills program at all. 
CHAPTER FIVE

Summary, Findings and Future Research

Introduction

The purpose of the study was to integrate a study

skills program into the curriculum of undergraduate, postsecondary adult students attending University of La Verne classes at Vandenberg Air Force Base and Naval Air station North Island. The following text will briefly restate the structure of this investigation. In the first section, a quick review of the literature is given. It addresses several key learning theories of the past 30 years, adult education and curriculum development, a couple of examples of study skills programs at the high school and college level, the study skills program for this project "Where There's A Will There's An 'A'", and the instrument of measurement, The Learning and study Strategies Inventory (IASSI). The second section reviews research questions and methodology; and, the final section discusses findings and future research.

\section{Eiterature Review}

An understanding of dominant, recent learning theories provided a foundation for building effective study skills 
programs. Many experts in the field agreed that learning produces change (Knowles, 1984). Change results in social and personal adjustments based upon new habits, attitudes and knowledge and causes adjustments in thinking and behavior that results in major adaptations to the environment to assure need fulfillment (Burton, 1963; Crow and Crow, 1963; Haggard, 1963). Developmental change is either the result of physical growth and maturation, or adjustments in the levels of capacity to handle tasks (Gagne, 1965). Gould (1978) believed that adaptations to life's many transitions enables adults to continue improvement on their learning skills. Although there was agreement that learning produces change, the origins of the learning process were often controversial.

Often experts within the field of learning theory argued among themselves. For example, Bruner (1966) contended that learning was developmental and competency based, but Jones (1966) argued that learning involved sophisticated levels of emotional and intellectual processes interacting. Skinner's (1968) opinion was that learning was the result of control and shaping through a set of elaborate conditions imposed on the subject. However, Maslow's (1972) humanitarian approach viewed learning as a self-actualizing, self-directed activity in which the individual engaged once basic needs of security and safety had been met. Three current views on learning that came into focus during the 
1980s were quantitative, qualitative, and a rekindling of Skinnerian behaviorism (Weinstein, Goetz, and Alexander, 1988) .

Malcom knowles (1984) led the way in developing a new learning theory based on the belief that learning styles differed between children and adults. Consequently he distinguished respectively between pedagogy and andragogy. Traditionally-aged college students, those between the ages of 18 and under 25 may have overlapping styles of learning; whereas, nontraditionally-aged adult college students are considered predominantly full-time employees and part-time students. This latter group has different agendas and styles of learning which commanded more experiential curricula. Study skills programs needed to address the differences in learning styles.

Many learning strategy programs removed participants from the primary site (job or classroom) and trained them in specific skills, after which they were to return to the primary site and apply what was learned. Programs in industry had employees attend seminars or inhouse courses where they would learn skills which management deemed needed.

In the past, some educators were under the assumption that students somehow naturally acquired study skills as they progressed through school (Brown et al., 1983). Yet, according to Anderson (1985) such study skills as problem 
solving, reasoning, decision making, and critical thinking, need to be taught, rehearsed and reviewed. The student is exposed to incoming information, processes the information, acts in terms of the new information and evaluates the actions. The way in which individuals learn about their world is delimited by the paradigms from which they operate. Information which does not fit within the periphery of the paradigm is not processed, but it is rejected (Mezirow, 1990). Students need to learn study skills that will teach them to dig deep and ask why something is, or why it is not. such double-loop learning helps in the solving of complex problems (Argyris, 1976); for example, it helps students identify and change "doom loops"--thinking processes which allow students to espouse one set of actions, yet execute a different set of actions (Argyris, 1991). The student learns how to challenge background assumptions about the information and formulate new ideas to be used in future problem solving situations.

Successful efforts in the integration of study skills programs into course curriculum have focused on the involvement of stakeholders. This group includes high level administrators, faculty, students, and anyone else who has a stake in the successful outcome of the intervention. Part of the design of an effective program should include the concept of understanding and questioning. It is through the process of a dialectic unfolding through questions and 
answers that learning takes place and visions are formulated and realized (Van der Meij, 1991).

The integrated and sequential study skills program, designed by Sensa Corporation, began at the University of San Diego High School in 1989. The Corporation selected a lead faculty person, sister Rose schmidt, to train in the use and application of a complex manual with related handouts. She was further trained in an inventory which was to be used as a pre and posttest to measure program success. Sister Rose used the summer months to train the school's regular faculty.

Working as a facilitator and program monitor, she made a number of discoveries. She found that an integrated and sequential study skills program was highly desirable. Qualitative feedback from students, staff, faculty, parents and administrators was good. She found the reality of having only select courses, such as social studies at the freshman level, and different select courses at each of the four levels of high school--freshman through senior-beneficial. Each course handling part of the integration of study skills was doable and appeared to be effective. However, she also identified several weaknesses.

Sensa Corporation had attempted to measure the success of the program quantitatively by designing a pre and posttest. This instrument lacked content and construct validity, for an example, many of the questions had little 
association with the material covered in the study skills course.

Sensa Corporation agreed that there were a number of program problems to address. They were always reevaluating their manuals and materials and refining them; and, they were currently working with expert judges on developing a better instrument (Nancy Shirley, Operations officer, for Sensa Corporation, personal communication, September, 1991). A number of postsecondary efforts at study skill programs have been made. Dr. L. Kochenderfer, of Riverside Community College, heads up a Learning Center, which offers in addition to standard tutorials, a number of freshman classes on learning to learn (Kochenderfer, personal communication, October, 1990). Professor Claire Weinstein, a learning strategies expert with the University of Texas at Austin, has developed a highly successful freshman course in Educational Psychology focused on learning to learn. Dr. Olney developed a seminar and consequently a series of video tapes called "Where There's A Will There's An 'A'" which covered 20 study skills techniques. These video tapes became the study skiils program for this study. Dr. Weinstein also worked with a team in the development of the Learning and study Strategies Inventory (LASSI) (Weinstein, 1987). The instrument was designed to be a diagnostic tool and to measure the effectiveness of intervention programs in a pre post test format on ten 
scales. The 77-item, Likert-type scale, self-reporting instrument had been deemed valid by expert judges and had a reliability correlation coefficient of .88 overall. This was the instrument selected for this study, for it was to measure the success of an intervention study skills program designed to address a particular problem.

\section{Research Questions And Methodology}

The problem this research addressed was developing an integrated study skills program into course curriculum for adult students in postsecondary classes at two of the University of La Verne's military locations. These two locations were at Vandenberg Air Force Base (VAFB) and Naval Air station North Island (NASNI).

The investigation focused on the following research questions, results of which are discussed under Findings and Future Research further on in this Chapter:

1. If there was a significant difference among three methodologies of a study skills program as measured by pre/ posttest differences on the LASSI inventory,

2. If there was a significant difference between traditional (traditionally-aged college students 18 to 25) and nontraditional (nontraditionally-aged college students over 25) measured by change means on the IASSI inventory,

3. If there was a significant difference between students in business classes and those in nonbusiness 
classes as measured by pre/posttest differences on the IASSI inventory,

4. If there was interaction between method and type of student as measured by the pre/posttest differences on LASSI inventory,

5. If there was interaction between method and type of class as measured by the pre/posttest differences on LASSI inventory,

6. If there was commonality in constructive comments on an exit interview,

7. If there was commonality in what was found most helpful on an exit interview, and

8. If there was commonality in what was found least helpful on an exit interview.

The integrated study skills program in this study was designed around Dr. Olney's film "Where There's A Will There's An 'A'." The program consisted of eight videos of the film. Three intact groups, a control group and treatment groups $A$ and $B$, were used in the quasi experimental design.

Treatment group A was exposed to method A, which consisted of exposure to six out of eight videos and a pre and post LASSI test. Treatment group $B$ involved the same as A with the addition of a study skills manual, which covered all 20 techniques, and a group discussion following each video viewing. The control group $c$ received no treatment 
and was only pre and post tested with the LASSI. The sample of 101 participants were divided as follows: 33 subjects in method A, 25 subjects in method B and 43 subjects in method c. These subjects were further subdivided into type of students (traditional or nontraditional) and classes (business or nonbusiness).

Students were called traditional (meaning traditionally aged college students 18 to 25 years) and nontraditional (nontraditionally-aged college students 25 and older who were primarily concerned with full-time jobs). Business classes held students who were business majors, with the exception of three students. Nonbusiness classes held students who were Psychology, Sociology, Criminology, Behavioral science, or undecided majors.

Two precursory steps were taken prior to the full scale study. A preliminary survey was administered to a convenience sample of 250 community college and University of Ia Verne Vandenberg Air Force Base and Naval Air Station North island adult undergraduate students asking if they felt the need for an integrated study skills program. Over $70 \%$ said they would like an integrated study skills program. Next four independent variables were selected to examine: Student, Method, Class, and Time. The model best suited for this investigation was a multivariate analysis, and SPSSX (1987) offered the software to facilitate the analysis. The software was built on an internal multiple regression 
analysis which converted results to the language of analysis of variance. Next a pilot study was run to assess the administrative procedures in addressing a full scale study at two separate sites. The pilot had 18 adult undergraduate students enrolled in University of La Verne classes at Naval Air Station North Island. Concerns with faculty resistance, student uncertainty and a poor quality of video tape were addressed and adjusted. Finally, the full study was conducted with adult undergraduates enrolled in University of La Verne classes at Vandenberg Air Force Base and Naval Air Station North Island.

The study drew inferences to the population which was described as a number of American based universities offering liberal arts and business degrees to adult undergraduate students attending programs on military installations both here and abroad. Although the sample was drawn only from the University of La Verne's military programs, it was hoped that inferences could be made about the overall population described.

Descriptive and inferential statistics were used to formulate results for the preliminary survey, pilot and full study. Frequency distributions and means were used to analyze results of the opinionnaire from the preliminary survey. Multiple analyses of variance was used to analyze data from the LASSI: A 4-way MANOVA on Student by class by Method by Time was used first, followed by two 3-way MaNOVAs 
on Location by Method by Time and Class by Method by Time; and finally, a 2-way MANOVA on Method by Time. Respective $\underline{F}$ tests on the 10 IASSI scales, which were the dependent variables, were run; then change means and their standard deviations were analyzed. Finally, select post hoc NewmanKeuls comparisons were calculated. An exit survey with three qualitative questions, which were discussed above, was administered to all participants in the pilot and field study. There were a number of significant findings. The closing section will discuss those findings briefly, reflect on methodological problems encountered, and suggest areas which may be conducive to further investigation.

\section{Findings and Future Research}

\section{Quantitative Questions}

Research findings and discussion focus on both quantitative and qualitative data. The significant quantitative discoveries involved the following: The passing of time had a significant affect on the impact a study skills program had on the subjects exposed to it. Significance lay in "within subject effects" and with specific interactions. Next, subjects' attitude toward the study skills program changed over time, in that enthusiasm declined. Finally, there was a notable difference between students in business classes and nonbusiness classes on 
several of the LASSI scales, which are summarized in an overview in Table 18. Qualitative information provided insight into several areas: Group discussions in treatment B did not always go as planned. Problems in the pilot which were thought to be resolved persisted. The outbreak of Operation Desert Storm, the Persian Gulf War of 1991, may have been a critical factor. The passing of time had a significant affect on the impact a study skills program had on the subjects exposed to it, when looking at "within subject effects." In a 3-way MANOVA Location by Method by Time within subject effect of Method by Time had a Wilks' Lambda equal to .6541 on 20 and 172 af which translated to a $\mathrm{p}$ value of .008 . Univariate $\mathrm{F}$ tests on the 10 LASSI scales revealed $\mathrm{p}<.05$ in Time Management, Information Processing, Use of Support Aids, and Self Testing. Newman-Keuls revealed that treatment $A, B$ or both $A$ and $B$ respectively were significantly different from the control group; and, in each case, students who received either treatment A or B improved in study skills on these four scales as measured by the LASSI self-report inventory. Improvement from exposure to a study skills program may be found for the population at large.

Significance lay in "within subject effects," as main effects in this study did not show a significant difference among the three methodologies. This could be attributed to the fact that the sample size was relatively 
Table 18

Grand summary

\begin{tabular}{|c|c|c|c|c|c|c|c|c|c|c|c|}
\hline Question & $\begin{array}{l}\text { Overall } \\
\text { statistical } \\
\text { significance }\end{array}$ & $A / T$ & $M / O$ & $T / M$ & $\begin{array}{l}\text { I Sce } \\
A / X\end{array}$ & $C / N$ & $\mathbf{I} / \mathbf{P}$ & SMI & S/A & $S / T$ & $T / T$ \\
\hline $\begin{array}{l}\text { 1. Method by } \\
\text { Time }\end{array}$ & $\begin{array}{l}\text { No }(4-\text { way }) \\
\text { Yes (3-way } \\
2 \text {-way) }\end{array}$ & & & $\stackrel{\text { A }}{\text { Improve }}$ & & & $\stackrel{\text { A }}{\text { Improve }}$ & & $\begin{array}{c}\text { B } \\
\text { Improve }\end{array}$ & $\begin{array}{c}\text { A B } B \\
\text { Improve }\end{array}$ & \\
\hline $\begin{array}{l}\text { 2. Student by } \\
\text { Time }\end{array}$ & No (4-way) & & & & & & & & & & \\
\hline $\begin{array}{l}\text { 3. Class by } \\
\text { Time }\end{array}$ & $\begin{array}{l}\text { Yes }(4-\text {-way }) \\
\text { Yes }(3 \text {-way })\end{array}$ & & $\begin{array}{l}\text { Bus. } \\
\text { Improve }\end{array}$ & $\begin{array}{l}\text { Bus. } \\
\text { Improve }\end{array}$ & & $\begin{array}{l}\text { Bus. } \\
\text { Improve }\end{array}$ & $\begin{array}{l}\text { Bus. } \\
\text { Improve }\end{array}$ & & $\begin{array}{l}\text { Bus. } \\
\text { Improve }\end{array}$ & & \\
\hline $\begin{array}{l}\text { 4. Student by } \\
\text { Method by } \\
\text { Time }\end{array}$ & No (4-way) & & & & & & & & & & \\
\hline $\begin{array}{l}\text { 5. Class by } \\
\text { Method by } \\
\text { Time }\end{array}$ & $\begin{array}{l}\text { "Close" (4-way) } \\
\text { Yes (3-way) }\end{array}$ & & & & & $\begin{array}{c}\text { B } \\
\text { Bus. } \\
\text { Improve }\end{array}$ & $\begin{array}{c}\text { A \& B } \\
\text { Bus. } \\
\text { Improve }\end{array}$ & & & $\begin{array}{c}\text { A \& B } \\
\text { Bus. } \\
\text { Improve }\end{array}$ & \\
\hline
\end{tabular}

Note: $A / T=$ Attitude; $M / O=$ Motivation; $T / M=T i m e$ Management $A / X=$ Anxiety; $C / N=$ Concentration; $I / P=$ Information Processing; SMI = Selected Main Ideas; $S / A=$ Support Aids; $S / T=$ Self Testing; T/T $=$ Test Taking. 
small to have a high enough power for such a robust statistical analysis as multivariate analysis. In future studies, it would be highly desirable to have a minimum of 100 participants complete the study in each of the categories: Student--100 nontraditional and 100 traditional, Class--100 business and 100 nonbusiness students. However, based upon earlier findings from personal communications as well as the literature review, within subject effect significance among methods was an anticipated outcome.

The passage of time affected attitude. In the 3-way MaNOVA, Class by Method by Time, within subject effect Time had a wilks' lambda equal to .7247 on 20 and 172 df which translated to a $\mathfrak{p}$ value of .001 . Univariate $\underline{F}$ tests on the IASSI scales showed attitude $\mathrm{p}<.05$. Mean change scores revealed a drop in scores for all three groups with no significance among groups. The enthusiasm toward the study skills program began to decline as the semester continued, according to the self-reporting results of the LASSI. This may also occur with the population.

one possible contributing factor to the decline in enthusiasm toward the study skills program could have been a general preoccupation with the Desert storm War. Since the study was conducted on military bases during this period of time, (January, 1991 through May, 1991) stress levels were high. Both installations upscaled from threatcon Alpha (a 
low level precautionary securing of the military base) to threatcon Bravo (a more stringent securing of the military installation) during the entire study. Recommendations for the future would include running a similar study during times of relative world peace when stress and anxiety levels may be less.

Another significant finding, and one which the researcher found particularly interesting, was the difference between students in business classes and those in nonbusiness classes. Looking solely at class by Time in the same 3-way MANOVA, Class by Method by Time, one discovers Wilks' Lambda of .7937 on 20 and 172 df which translated to a $\mathbf{p}$ value of .023 . Univariate $\underline{F}$ tests on the 10 LASSI scales showed $\mathrm{Q}<.05$ in five areas: Motivation, Time Management, Concentration, Information Processing and Use of Support Aids. An examination of change means and their standard deviations showed that business students consistently out-performed nonbusiness students on the LASSI in these five areas. The population overall might display the same results: Both groups do better as time passes; yet business students do better than nonbusiness students. of course, the obvious question rests in whether the students improved on these five scales because of the regular curriculum, or because of a particular methodology in the study skills program. The next step was to examine Method by class by Time. 
The within subject effect had a Wilks' lambda equal to .6919 on 20 and 172 df which translated to a p of .031. Univariate $\underline{F}$ tests on the LASSI scales showed significance of $\mathrm{p}<=.05$ on Anxiety, Concentration, Information Processing and self-testing. The interesting discovery was that business students IASSI scores decreased in the control group on all four scales and increased with exposure to either treatment A or B. Conversely, nonbusiness students LASSI scores increased in the control group and decreased in either treatment group A or B. This discovery led to some interesting thoughts.

Perhaps business students have specific needs for a particular kind of study skills program which differs from the needs of nonbusiness students. Although the business students improved in either groups A or B, by and large they improved the most with treatment $A$, which was the brief exposure to a study skills program without the manual or the group discussion. The researcher's bias was that the manual and group discussion was the critical component, but in this study that turned out not to be the case when comparing business versus nonbusiness students. Reasons for this phenomena again could be the small sample size, or the possible high stress levels, which might have contributed to a lack of concentration to a manual or group discussion. Thus, inferences to the population are made with caution. Again, the recommendation would be to replicate the study 
with a much larger sample size. Table 18 gives an overview of the impact of the methodologies on business and nonbusiness students on the ten LASSI scales.

Pulling together all the various MANOVA test results which were run on the ten IASSI scales, patterns of significant results emerge. Table 18 captures a macro view of the phenomena that was observed. Question \#1 looked at Method by Time. There were no significant findings at the 4-way MANOVA level, however, since Time alone was significant and the researcher was curious to investigate this question further, a 3-way MANOVA on Location by Method by Time was run. Method by Time surfaced as significant in this 3-way MANOVA as discussed above. LASSI scales of significance were Time Management, Information Processing, use of Support Aids and Self-Testing. The 2-way MANOVA Method by Time showed the exact same IASSI scales as significant.

Question \#2 student by Time and \#4 Student by Method By Time involved type of student. Type of student was not significant in the 4-way MANOVA and thus was dropped from further examination. As mentioned earlier, this may be attributed to the highly unequal distribution of traditional and nontraditional students, and again the recommendation would be to have adequate sample sizes in this variable for replication. 
Question \#3 examined class by Time. This was significant in the 4-way MANOVA. It was also significant in the 3-way MANOVA Class by Method by Time on the scales of Motivation, Time Management, Concentration, Information Processing and use of Support Aids.

Question \#5 determined that Class by Method by Time showed a trend toward significance in the 4-way MANOVA having $\underline{p}>$ but close to .05 . The 3-way MaNOVA class by Method by Time showed significance on these scales: Anxiety, Concentration, Information Processing and SelfTesting.

Patterns in Table 18 show that several scales repeatedly surfaced as significant. They were Time Management, Concentration, Information Processing, use of Support Aids and self-Testing. It was also evident that either Method A or Method B or both could be effective on some scales as opposed to doing nothing at all. In fact, these 5 out of the 10 scales showed significant change from having an intervention program. Further, students in business classes consistently improved over students in nonbusiness classes.

An additional comment prior to moving into a discussion on the qualitative section would be what constitutes a proper exposure to the study skills program. This means specifically how many sessions of the video tape should be seen. For this study the cut off was 6 tapes out of 8 
constituted exposure to the study skills program. Tapes were kept in the office at both Vandenberg Air Force Base and Naval Air Station North Island and consequently, students did not have access to any missed sessions. This may also have had some impact on outcomes. The recommendation for a similar study would be to have all tapes accessible to students at all times.

\section{Qualitative ouestions}

students overall liked having a study skills program integrated into course curriculum. Problems with the quality of tape, which were addressed by students at both locations and in treatment groups $A$ and $B$, did surface during the pilot study. However, the tapes were prepared again from the master and they appeared to be adequate for the full scale study. Obviously, the quality of the tape continued to be of concern to students. A suggestion for further use would be to use only the master tapes, which can be purchased through Dr. Claude olney, or to design one's own study skill tapes.

other suggestions from students on what they liked most were the theories of studying smarter. Fewer testimonials and more direct applications may be helpful in the future. Additionally, they found many of the 20 techniques helpful and were able to apply them in other courses. 
Finally, comments on what was liked least covered several areas. One student's comment from treatment group B pointed out that the instructor's challenging of the video presenter's ideas and the student's own study habits was disturbing, and this attempt at provoking critical thinking on the part of the instructor may have backfired with this expressive student. It may have affected others who did not voice an opinion, and this reaction could have been caused by general anxiety and stress levels over the Desert storm war. Some students were irritated by the level of the presentation. This changes direction to the University of San Diego High School model which was designed by Sensa Corporation. A more integrated and sequential study skills program would probably work out better. Their program selects target classes at each level grades nine through twelve, and it focuses on specific study skills techniques with lots of application to course content and current problems. A future study skills program for postsecondary might attempt the same model.

Faculty on the exit survey had similar comments. First they expressed a desire to relate the subject matter to the students' level in school. Next they felt the quality of the tapes needed improving, and taped material needed further editing to remove excess testimonials. Also, faculty were initially resistant to integrating the study skills program into course curriculum. They resented the 
imposition on their time, and they felt that their curriculum was already too crowded to fit in one more thing. Several factors helped to facilitate the introduction of the study skills program.

Three lead faculty were selected to run the pilot, which they handled with enthusiasm and with dedication. These instructors were available to answer any questions for other faculty who would be involved in the full study; and in fact, some of them were contacted by faculty from the full study. The pilot instructors' support was crucial to the facilitation of the full study. In recommending how one would go about implementing an integrated study skills program on their on campus, it would be wise to draw upon the experience of those who have successfully done so. Dr. Claire Weinstein of the University of Texas at Austin has been successful in the development and implementation of her own study skills program. Her dedication, expertise and creativity, have been elements for effectiveness. Sister Rose schmidt was a highly effective facilitator at the secondary level for Sensa Corporation in San Diego, california. When asked what she attributed her success to, she stated that she believed in the program and was able to deliver it with sincerity and enthusiasm (Schmidt, personal communication, October, 1991) The researcher's own experience with this study has reinforced that concept, in 
that the instructors who participated in the pilot were able to encourage other faculty to try the program.

The length of a study skills program is controversial. Dr. Claude olney believes that a one day seminar on study techniques is enough to launch a student on a college career of obtaining straight As and dramatically improving one's academic self-concept. On the other hand, Dr. Claire Weinstein has developed a series of semester long courses and advocates faculty incorporating study strategies into course curriculum. Sensa corporation contends that it takes years of training and that study skills should be both integrated and sequential, extending over one's school years to reinforce moving intellectually from theory to application. The researcher's opinion is that an integrated and sequential program is the most desirable, but length of time depends on individual differences among students. The utilization of the IASSI as a tool to measure intervention worked and the researcher would consider using this instrument for this type of study in the future. The LASSI is designed to measure growth on a one time intervention or a series of interventions over an extended period of time. Again the degree of change depends on the individuals involved in the study. The practical significance of the time involved to obtain a change depends on the dedication and perseverance of the faculty and students working as a team. Any degree of change in a 
positive direction which could facilitate an individual reaching toward maximum potential is worth the effort in the minds of a majority of teachers who are dedicated to their profession.

The LASSI, like a number of other inventories on the market today, e.g., Sensa Corporation's, are continually under evaluation and revision. The IASSI is currently being revised with expansion of scales with less than 10 items, and it is reviewed for an update in validity periodically by expert judges. The instrument has a high degree of validity, and it has an overall reliability correlation coefficient of .88 , which is very good (Anastasia, 1976). Norms are a weak area, in that norms would need to be developed for the specific population with which the inventory is being used. For example, in a replicated study, one might desire to develop norms for adult students attending American based universities which offer business programs on military installations.

Postsecondary education can be made more fulfilling for adult students by designing curriculum that meets their unique needs. One way in which educational leaders can accomplish this is to investigate ways in which study skills programs, which are integrative and sequential, can be added to the course curriculum.

Several implications arose from the study. First, the literature review indicated that young adult students, or 
traditionally-aged college students between 18 and 25 , may need more direction in their curriculum as advocated in the pedagogical methods of instruction. Thus study skills programs would need to be designed differently from those that would address the needs of nontraditionally-aged adult students. Next, an andragogical approach, which allows for the student to be self-directed and utilizes the adult's life experiences, would be more appropriate for study skills programs focused on the latter population.

Finally, results from this study implied that there may be the origins of a theory which could address specific needs which nontraditional adult business students in this population have in specific developmental phases of their Iife span. 
References

Amatea, E. S., \& Sherrard, P. A. D. (1991, March/April). When students cannot or will not change their behavior: Using brief strategic intervention in the school. Journal of Counseling \& Development, 69, 341-343.

Anastasia, A. (1976). Psychological testing. New York: Macmillan.

Anderson, J. R. (1985). Cognitive psychology and its implications. San Francisco: Freeman.

Anderson, L. W., \& Jones, B. F. (1981). Designing instructional strategies which facilitate learning for mastery. Educational Psychologist, 1, 121-138.

Argyris, C. (1991, May-June). Teaching smart people how to learn. Harvard Business Review, p. 103.

Argyris, c. (1976) - Increasing leadership effectiveness. New York: Wiley-Interscience.

Arkin, H., \& Colton, R. R. (1963). Tables for statisticians. New York: Barnes \& Noble. 
Bandura, A. (1982). Self-efficacy mechanism in human agency. American Psychologist, 37(2), 122-147.

Bimes-Michalak, B. (1988). More than a writing program. Basic Education, 33, 13-15.

Bloom, B. (1956). Taxonomy of educational objectives. New York: David McKay.

Brooksfield, S. D. (1987). Developing critical thinkers. San Francisco: Jossey-Bass.

Brown, A. L., Bransford, W. F., Ferrera, R., \& Campione, J. (1983). Learning, remembering, and understanding. In J. Flavell and E. Markman (Eds.). The handbook of Child Psychology (Vol. 3). New York: Wiley.

Brown, J. I., Nelson, M. J., \& Denny, E, C. (1973) . Nelson-Denny reading test. Boston: Houghton Mifflin. In C. E. Weinstein, E. T. Goetz \& P. A. Alexander (Eds.), Learning and study strategies. San Francisco: Academic Press, Inc.

Bruner, J. S. (1966). Toward a theory of instructon. Cambridge, MA: Harvard University Press. 
Burton, w. H. (1963). Basic principles in a good teachinglearning situation. In L. D. and Alice Crow (Eds.), Readings in human learning (pp. 7-19). New York: McKay .

California Task Force. (1990). Toward a state of esteem. Sacramento, CA: California State Department of Education.

Carrier, C. A. (1987, June). Technology assisted adult learning. Training \& Development Journal, p. 98.

Chickering, A. w. (1976). Education and identity. San Francisco: Jossey-Bass.

Cross, K. P. (1981). Adults as learners. San Francisco: Jossey-Bass.

Crow, I. D., \& Crow, A. (Eds.) (1963). Readings in human learning. New York: McKay.

Crown, D., \& Marlowe, D. (1964). The approval motive. New York: Wiley. In C. E. Weinstein, E. T. Goetz, \& P. A. Alexander (Eds.), Learning and study strategies. New York: Academic Press, Inc. 
Dansereau, D. F. (1985). Learning strategy research. In

J. Segal, S. Schipman, \& R. Glaser (Eds.), Relating

instruction to basic research. Hillsdale, NJ:

Erlbaum.

Dansereau, D. F., Collins, K. W., McDonald, B. A., Holley,

C. D., Garland J., Diekhoff, G., \& Evans, S. H.

(1979). Development and evaluation of a learning

strategy training program. Journal of Educational

Psychology, 71, 64-73.

Egan, G. (1986). The skilled helper: A systematic approach to effective helping. Monterey, CA: Brooks/Cole.

Feuer, D., \& Geber, B. (1988, December). Uh-oh . . second thoughts about adult learning theory. Training: The Magazine of Human Resources Development, 25, p. 31.

Gagne, R. M. (1965). The conditions of learning. New York: Holt Rinehart and Winston.

Gould, R. L. (1978). Transformations: Growth and change

in adult life. New York: Simon \& schuster.

Greene, M. (1986). In search of critical pedagogy. Harvard Educational Review, $\underline{56}(4)$, 427-441. 
Haggard, E. A. (1963). Learning a process of change. In L. D. Crow and Alice Crow (Eds.), Readings in human learning (pp. 19-27). New York: McKay.

Jacks, I. P. (1929, February). Journal of Adult Education. I(1), pp. 7-10. In M. Knowles, The adult learner: A neglected species. Houston TX: Gulf.

Jones, R. M. (1966). Fantasy and feeling in education. New York: University Press.

Kerner, R. W. (1991, spring). Understanding the application of learning. New Directions for Adult and Continuing Education, pp.67-80.

Knowles, M. (1989, August). Everything you wanted to know from Malcolm Knowles (and weren't afraid to ask). (Interview with author Malcolm knowles). Training: The Magazine of Human Resources Development, $26(8)$, pp. 45-46.

Knowles, M. (1984). The adult learner: A neglected species. Houston, TX: Gulf.

Knowles, M. S. (1970). The modern practice of adult education: Andragogy versus pedagogy. New York: Association Press. 
Knox, A. B. (1988, June) - Helping adults apply what they learn. Training and Development Journal, pp. 55-59.

Lindeman, E. C. (1938, October). Journal of Adult Education $\mathrm{X}(4), \mathrm{pp} \cdot 385-386$. In M. Knowles, The adult learner: A neglected species. Houston, TX: Gulf.

Lindeman, E. C. (1926). The Meaning of adult education. New York: New Republic. In M. Knowles, The adult learner: A neglected species. Houston, TX: Gulf.

Machiavelli. (1974). The prince. C. E. Detmold \& L. G. Crocker (ed.), (Trans.). New York: Washington Square Press. (Original work printed in 1525).

Mager, R. F. (1968). Developing attitude toward learning. Belmont, CA: Feron.

Mangan, K. S. (1988, September 14). A pioneer in teaching "learning to learn" skills. The chronicle of Higher Education, p. A3.

Maslow, A. H. (1972). Defense and growth. In M. L. Silberman, et al. (Eds.), The psychology of open teaching and learning. Boston, MA: Little Brown, pp. 43-51.

Mayer, R. E. (1984). Aids to text comprehension. Educational Psychologist, 19, 30-42. 
Mayer, R. E. (1988). Learning strategies: An overview.

In C. E. Weinstein, E. T. Goetz \& P. A. Alexander (Eds.), Learning and study strategies. New York: Academic Press, Inc.

Mealey, D. I. (1988, January). Test review: Learning and study strategies inventory (LASSI). Journal of Reading, $31(4), 382-385$.

Meyers, C. (1986). Teaching students to think critically: A quide for faculty in all disciplines. San Francisco: Jossey-Bass.

Mezirow, J., \& Associates. (1990). Fostering critical reflection in adulthood. San Francisco: Jossey-Bass.

Noel, I., \& Levitz, R. (Eds.). (1982). How to succeed with academically underprepared students. Iowa City: American College Testing Service National Center for Advancing Educational Practice.

Popham, W. J. (1967). Educational statistics: Use and intrepretation. New York: McGraw-Hill.

Rudolph, B. A. (1990, May) . A self-assessment procedure on concurrency. Communications of the $A C M, 33(5), p .583$. 
Russell, J. E. (1938, October). Journal of Adult Education, $\underline{X}(R), 385-386$. In M. Knowles, The adult learner: A neglected species. Houston, TX: Gulf.

Saxe, S. (June, 1988). Peer influence and learning. Training and Development Journal, 42, p. 50 .

Schmeck, R. R., Ribich, F., \& Ramanaiah, N. (1977). Development of a self-report inventory for assessing individual differences in learning processes. Applied Psychological Measurement, 1, 413-431. In C. E. Weinstein, E. T. Goetz \& P. A. Alexander, Learning and study strategies. New York: Academic Press, Inc.

Skinner, B. F. (1968). The technology of teaching. New York: Appleton-Century-crofts.

Spielberger, C. D., Gonzalez, H. P., Taylor, C., Algaze, J., \& Anton, W. E. (1978). Examination, stress and test anxiety. In C. D. Spielberger \& I. G. Sarason (Eds.), Anxiety and stress (Vol. 5). New York: Hemisphere/wiley.

Spielberger, C. D., Gorsuch, R. I., \& Luschene, R. E. (1970). Manual for the State-Trait Anxiety Inventory. Palo Alto, CA: Consulting Psychologists Press.

Taft, R. J. (spring, 1991) . Handling change creatively. New Directions For Higher Education, 73, 75-94. 
Thorndike, E. (1938). Adult abilities. In M. Knowles, The adult learner: A neglected species. Houston TX: Gulf.

Thorndike, E. (1935). Adult interest. In M. Knowles, The adult learner: A neglected species. Houston TX: Gulf.

Thorndike, E. (1928). Adult learning. In M. Knowles, The adult learner: A neglected species. Houston, TX: Gulf.

Van der Meij, H. (1991). Understanding as the key to effective questioning. Journal of Curriculum studies, $\underline{23}(4), 357-376$.

Wang, M. C., Haertel, G. D., \& Walberg, H. J. (1990). What influences learning? A content analysis of review Iiterature. The Journal of Educational Research, $\underline{84}(1), 30-43$.

Weinstein, C. E., Ridley, D. S., Dahl, T., \& Weber, E. S. (1988, December/January, 1989). Helping students develop strategies for effective learning. Educational Leadership, pp. 17-19.

Weinstein, C. E., Goetz, E. T., Alexander, P. A. (1988). Learning and study strategies. New York: Academic Press. 
Weinstein, C. E., Zimmermann, S. A., \& Palmer, D. R. (1988). Assessing learning strategies: The design and development of the IASSI. In C. E. Weinstein, E. T. Goetz \& P. A. Alexander (Eds.), Learning and study strateqies. New York: Academic Press, Inc.

Weinstein, C. E. (1987). The learning and study strategies inventory (IASSI) user's manual. Clearwater, FL: H \& H Publishing Co.

Weise, M. (1939). Journal of Adult Education, XI, 174-175. In M. Knowles, The adult learner: A neglected species. Houston, TX: Gulf.

Wilson, J.E. (1988). Implications of learning strategy research and training: What it has to say to the practitioner. In C. E. Weinstein, E. T. Goetz, \& P. A. Alexander (Eds.), Learning and study strategies. New York: Academic Press, Inc.

Wlodkowski, R. J. (1985). Enhancing adult motivation to learn: A quide to improving instruction and increasing learner achievement. San Francisco: Jossey-Bass. 
Appendix A

opinionnaire

SURVEY

SURVEY

SURVEY

Dear student,

Would you find it helpful to your college career to have a brief lesson once a week on some aspect of learning strategies for the adult student? This approximate 7 minute lesson would be presented during your regular class time in the evening to help you be better prepared for the class.

YES

No

If you answer YES, please indicate by numbering the following topics according to most important (1) to least important (9) that you would be interested in having presented.

How to prepare for and review for class.

How to utilize support materials.

How to prepare for and take tests.

How to increase concentration.

How to identify main ideas.

How to increase self-confidence in academic performance.

How to better manage time.

How to be self-motivating.

How to develop a positive attitude

toward difficult courses. 
February 4, 1991

Dr. Claude Olney

P.O. Box 686

Scottsdale, AZ 85252

Dear Dr. Olney,

It was delightful talking with you this afternoon! I am enclosing a check in the amount of $\$ 89.95$ to cover the cost of the video "Where There's A Will There's An A."

I appreciate your giving me permission to use your video in my doctoral dissertation. I am interested in learning how the adult student participants' self perceptions on the LASSI scales which we discussed will change after exposure to the seminar.

Thanks for the additional advice regarding possible concerns in handling of the control group. I will address this issue in the study. I also value your sharing the additional examples which were left out of the first video for college students. I think the post-it notes in books and the study interval approach to learning a subject is great.

I would also like to take a moment to add that I feel very sympathetic about the recent loss of your wife. It is always a very difficult time, and I hope that God and your family and good friends will help to ease your way.

I am grateful for all your help. If you have any additional questions regarding the study, please call.

sincerely,

Pam Priest

Director

University of La Verne

Residence Center

NAS North Island 
February 20, 1991

VANDENBERG AFB

NAS NORTH ISLAND

Dear Instructor:

The University of La Verne School of Continuing Education has approved a research project on study skills to run during the spring 1991 semester at NAS North Island and Vandenberg AFB. Instructors at these two locations will be in one of the three groups.

The study skills program will involve a video produced by Dr. Olney of Arizona State University.

You will be contacted shortly regarding a faculty meeting which will discuss the group your class will be in and what your brief role will be in participating in this program.

Your cooperation is deeply appreciated, and the researcher, Pam Priest, Director of NAS North Island branch and her Associate, Evie Hardin, Director of the Vandenberg branch will contact you soon. 
Appendix D

February 20, 1991

GROUP B INSTRUCTORS

Dear _ :

There will be a 30 minute faculty meeting on at in room $\cdot$

The purpose of this meeting is to go over the procedures for conducting the study skills program in your course during this semester.

It is very important that you attend this meeting. Thanks very much for your support and cooperation. It is greatly appreciated.

Pam Priest

Director

NAS NO. IsI CTR. 


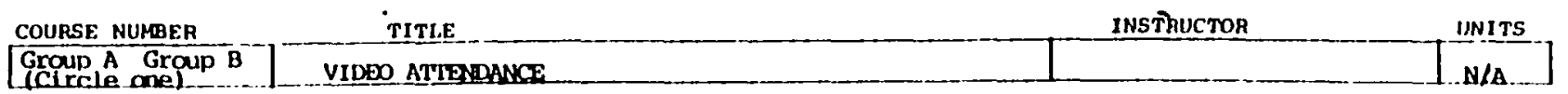

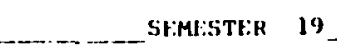

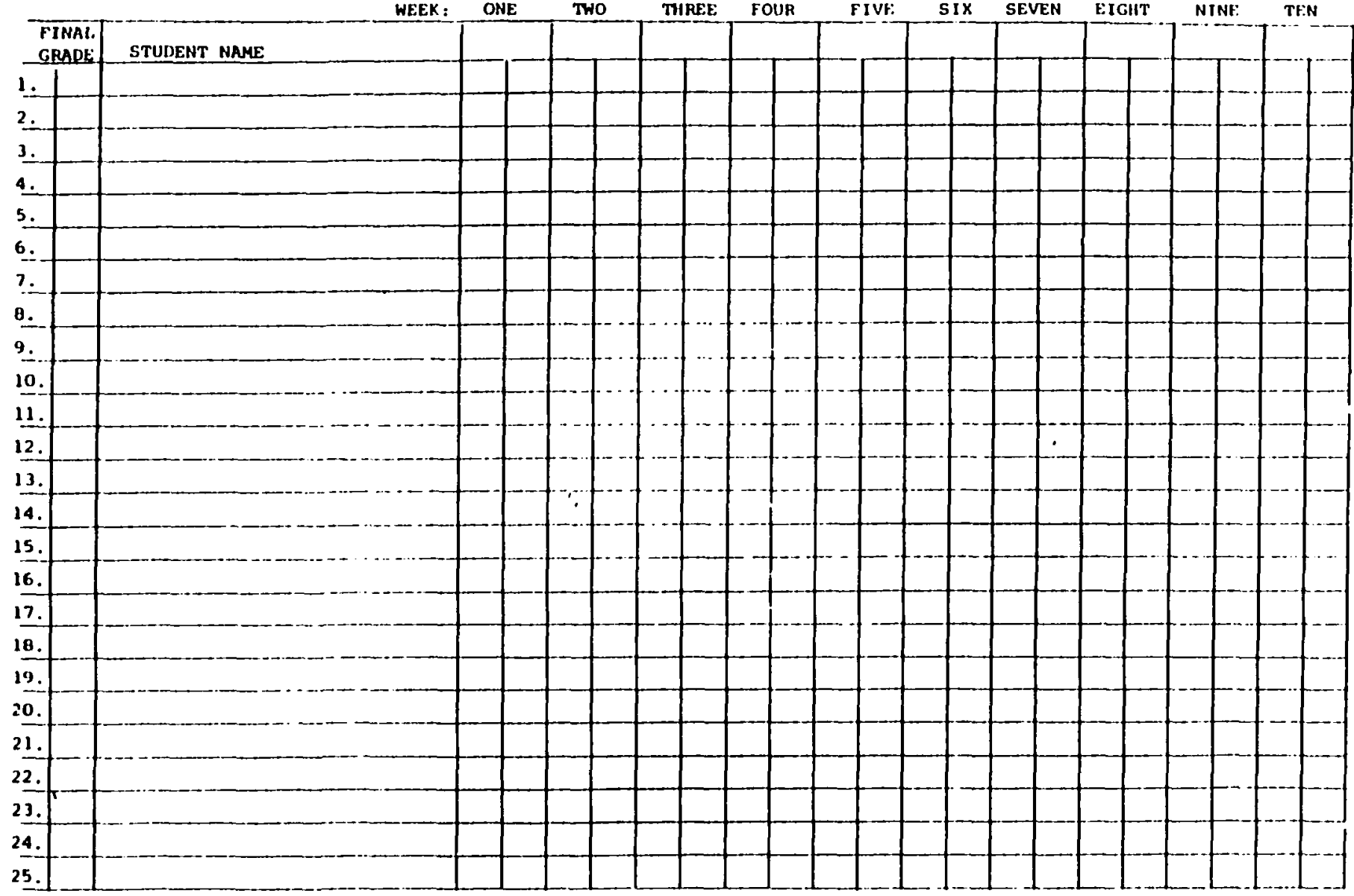


Appendix $F$

FORM C - CONSENT FORM

Title of Research: The Impact of a study Skills Program on University of Ia Verne Adult Undergraduates at Vandenberg

Air Force Base and Naval Air Station North Island.

Conducted by: Pam Priest

Doctoral Candidate

University of San Diego

1. I understand that the purpose of this study is to assess the effectiveness of a study skills program.

2. I understand that I will be taking the LASSI learning skills inventory twice.

3. I understand that my LASSI scores will be kept confidential.

4. I understand that I am welcome to have my LASSI scores interpreted to me.

5. I understand that there are no risks to me in taking the IASSI test for 15 minutes twice.

6. I understand that there may be potential benefits which could be gained through an understanding of the IASSI results.

7. I understand that participation in this study is voluntary and I may withdraw at any time.

8. I have had the opportunity to ask questions about the study and procedures and have had all questions satisfactorily answered.

9. I understand that there is no agreement, written or verbal, beyond that expressed on this consent form.

I, the undersigned, confirm the above statements and give consent to my voluntary participation in this study.

Participant's Signature last 4 digits of social security

Researcher's Signature
Signed this day of di California.
at


Aependix $G$

FACULTY CONSENT FORM

Spring, 1991

NAS North Island

Vandenberg AFB

I have attended a faculty meeting addressing the research project on Study Skills Programs which will run during the spring, 1991 semester. I understand that I am in group and know the specific instructions for my group. If I am a group A or B instructor, I will keep attendance records on those students participating in the project. 
Appendix $\mathrm{H}$

LIST OF DIRECTIONS FOR GROUP B INSTRUCTORS

1. Administer LASSI pretest.

2. Show section 1 through 8 of video "Where There's A Will There's An 'A'", each section at a different class session.

3. Using the appropriate section of the accompanying manual, lead a group discussion which explores both students' and video presenter's background assumptions about study skills.

4. Demonstrate at least one application of the technique(s) learned in the video section to content within your subject area.

5. At the conclusion of the study skills program, administer IASSI posttest. 
Appendix I

Exit Survey Form for students and Faculty

Dear student,

You have recently participated in a (pilot) study of a study skill intervention program (the video called "Where There's A will There's An A").

Your feedback and constructive suggestions would be a lot of help.

Please answer the following:

1. The video sessions could be improved by . . .

2. The part I found most helpful was . .

3. The part I found least helpful was... 


\section{Appendix J}

Pre and Posttest Means and Standard Deviations for Business and Nonbusiness Classes on 10 LASSI scales

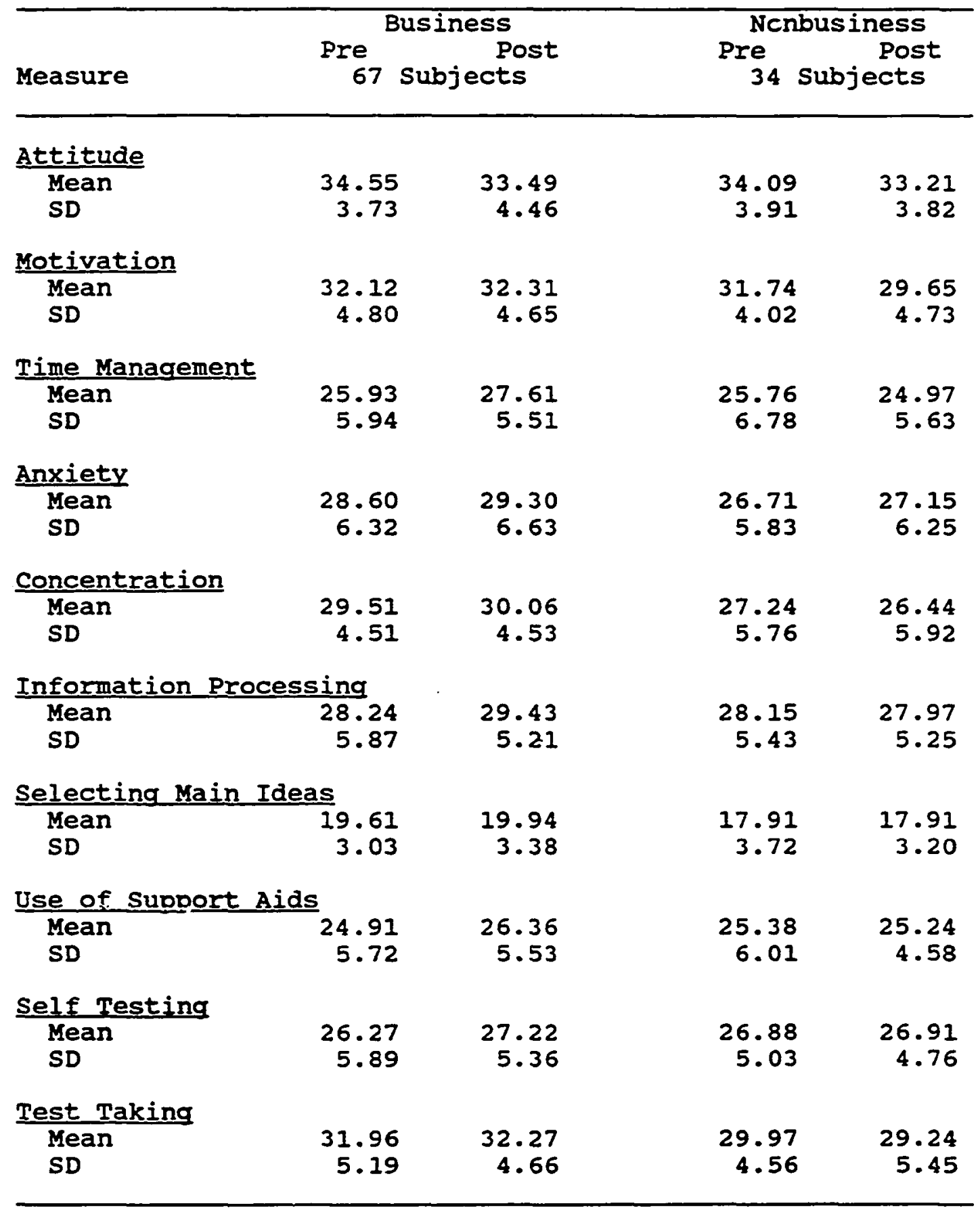

Note: $\mathbf{N}=101$. 
Appendix $\mathrm{K}$

Pre and Posttest Means and Standard Deviations for Methods $C_{1} B_{1}$ and $A$ on 10 LASSI scales

\begin{tabular}{|c|c|c|c|c|c|c|}
\hline \multirow[b]{2}{*}{ Measure } & \multicolumn{2}{|c|}{$\frac{C}{c}$} & & \multicolumn{2}{|c|}{25 Subjects } \\
\hline & Pre & Post & Pre & Post & Pre & Post \\
\hline \multicolumn{7}{|c|}{ Attitude } \\
\hline $\begin{array}{l}\text { Mean } \\
\text { SD }\end{array}$ & $\begin{array}{r}34.58 \\
3.45\end{array}$ & $\begin{array}{r}33.86 \\
3.62\end{array}$ & $\begin{array}{r}34.76 \\
3.72\end{array}$ & $\begin{array}{r}33.55 \\
4.94\end{array}$ & $\begin{array}{r}33.60 \\
4.40\end{array}$ & $\begin{array}{r}32.40 \\
4.21\end{array}$ \\
\hline \multicolumn{7}{|c|}{ Motivation } \\
\hline $\begin{array}{l}\text { Mean } \\
\text { SD }\end{array}$ & $\begin{array}{r}32.60 \\
4.50\end{array}$ & $\begin{array}{r}32.05 \\
4.77\end{array}$ & $\begin{array}{r}32.27 \\
4.55\end{array}$ & $\begin{array}{r}31.18 \\
5.01\end{array}$ & $\begin{array}{r}30.56 \\
4.43\end{array}$ & $\begin{array}{r}30.64 \\
4.72\end{array}$ \\
\hline \multicolumn{7}{|c|}{ Time Management } \\
\hline $\begin{array}{l}\text { Mean } \\
\text { SD }\end{array}$ & $\begin{array}{r}27.67 \\
6.88\end{array}$ & $\begin{array}{r}27.12 \\
6.54\end{array}$ & $\begin{array}{r}24.55 \\
5.20\end{array}$ & $\begin{array}{r}26.73 \\
4.48\end{array}$ & $\begin{array}{r}24.52 \\
5.58\end{array}$ & $\begin{array}{r}26.04 \\
5.58\end{array}$ \\
\hline \multicolumn{7}{|l|}{ Anxiety } \\
\hline $\begin{array}{l}\text { Mean } \\
\text { SD }\end{array}$ & $\begin{array}{r}27.88 \\
7.37\end{array}$ & $\begin{array}{r}28.58 \\
7.01\end{array}$ & $\begin{array}{r}28.97 \\
4.89\end{array}$ & $\begin{array}{r}30.06 \\
5.69\end{array}$ & $\begin{array}{r}26.76 \\
5.50\end{array}$ & $\begin{array}{r}26.60 \\
6.54\end{array}$ \\
\hline \multicolumn{7}{|c|}{ Concentration } \\
\hline $\begin{array}{l}\text { Mean } \\
\text { SD }\end{array}$ & $\begin{array}{r}29.53 \\
5.72\end{array}$ & $\begin{array}{r}29.37 \\
4.66\end{array}$ & $\begin{array}{r}28.91 \\
4.35\end{array}$ & $\begin{array}{r}28.97 \\
5.62\end{array}$ & $\begin{array}{r}27.16 \\
4.51\end{array}$ & $\begin{array}{r}27.76 \\
5.92\end{array}$ \\
\hline \multicolumn{7}{|c|}{ Information Processing } \\
\hline $\begin{array}{l}\text { Mean } \\
\text { SD }\end{array}$ & $\begin{array}{r}29.30 \\
5.23\end{array}$ & $\begin{array}{r}28.65 \\
5.19\end{array}$ & $\begin{array}{r}26.85 \\
5.87\end{array}$ & $\begin{array}{r}28.52 \\
5.77\end{array}$ & $\begin{array}{r}28.12 \\
6.06\end{array}$ & $\begin{array}{r}30.00 \\
4.63\end{array}$ \\
\hline \multicolumn{7}{|c|}{ Selecting Main Ideas } \\
\hline $\begin{array}{l}\text { Mean } \\
\text { SD }\end{array}$ & $\begin{array}{r}19.47 \\
3.43\end{array}$ & $\begin{array}{r}19.44 \\
3.36\end{array}$ & $\begin{array}{r}18.89 \\
3.57\end{array}$ & $\begin{array}{r}19.15 \\
3.41\end{array}$ & $\begin{array}{r}18.52 \\
2.96\end{array}$ & $\begin{array}{r}19.08 \\
3.73\end{array}$ \\
\hline \multicolumn{7}{|c|}{ Use of Support Aids } \\
\hline $\begin{array}{l}\text { Mean } \\
\text { SD }\end{array}$ & $\begin{array}{r}26.30 \\
5.73\end{array}$ & $\begin{array}{r}25.91 \\
5.10\end{array}$ & $\begin{array}{r}24.33 \\
5.00\end{array}$ & $\begin{array}{r}25.45 \\
5.66\end{array}$ & $\begin{array}{r}23.92 \\
6.65\end{array}$ & $\begin{array}{r}26.80 \\
4.98\end{array}$ \\
\hline \multicolumn{7}{|c|}{ Self Testing } \\
\hline $\begin{array}{l}\text { Mean } \\
\text { SD }\end{array}$ & $\begin{array}{r}27.72 \\
5.27\end{array}$ & $\begin{array}{r}26.47 \\
5.44\end{array}$ & $\begin{array}{r}25.27 \\
5.16\end{array}$ & $\begin{array}{r}27.00 \\
5.29\end{array}$ & $\begin{array}{r}25.92 \\
6.44\end{array}$ & $\begin{array}{r}28.40 \\
4.31\end{array}$ \\
\hline \multicolumn{7}{|c|}{ Test Taking } \\
\hline $\begin{array}{l}\text { Mean } \\
\text { SD }\end{array}$ & $\begin{array}{r}31.67 \\
5.63\end{array}$ & $\begin{array}{r}32.05 \\
4.41\end{array}$ & $\begin{array}{r}31.24 \\
4.96\end{array}$ & $\begin{array}{r}31.70 \\
4.86\end{array}$ & $\begin{array}{r}30.68 \\
4.17\end{array}$ & $\begin{array}{r}29.28 \\
6.17\end{array}$ \\
\hline
\end{tabular}

Note: $N=101$. 
Appendix L

Pre and Posttest Means and Standard Deviations for Entire Population on 10 IASSI scales

\begin{tabular}{|c|c|c|}
\hline Measure & Subjects* & Post \\
\hline \multicolumn{3}{|c|}{ Attitude } \\
\hline $\begin{array}{l}\text { Mean } \\
\text { SD }\end{array}$ & $\begin{array}{r}34.40 \\
3.78\end{array}$ & $\begin{array}{r}33.40 \\
4.24\end{array}$ \\
\hline \multicolumn{3}{|c|}{ Motivation } \\
\hline $\begin{array}{l}\text { Mean } \\
\text { SD }\end{array}$ & $\begin{array}{r}31.99 \\
4.53\end{array}$ & $\begin{array}{r}31.42 \\
4.83\end{array}$ \\
\hline \multicolumn{3}{|c|}{ Time Management } \\
\hline $\begin{array}{l}\text { Mean } \\
\text { SD }\end{array}$ & $\begin{array}{r}25.87 \\
6.20\end{array}$ & $\begin{array}{r}26.72 \\
5.66\end{array}$ \\
\hline \multicolumn{3}{|l|}{ Anxiety } \\
\hline $\begin{array}{l}\text { Mean } \\
\text { SD }\end{array}$ & $\begin{array}{r}27.96 \\
6.20\end{array}$ & $\begin{array}{r}28.57 \\
6.55\end{array}$ \\
\hline \multicolumn{3}{|c|}{ Concentration } \\
\hline $\begin{array}{l}\text { Mean } \\
\text { SD }\end{array}$ & $\begin{array}{r}28.74 \\
5.06\end{array}$ & $\begin{array}{r}28.84 \\
5.30\end{array}$ \\
\hline \multicolumn{3}{|c|}{ Information Processing } \\
\hline $\begin{array}{l}\text { Mean } \\
\text { SD }\end{array}$ & $\begin{array}{r}28.21 \\
5.70\end{array}$ & $\begin{array}{r}28.94 \\
5.24\end{array}$ \\
\hline \multicolumn{3}{|c|}{ Selecting Main Ideas } \\
\hline $\begin{array}{l}\text { Mean } \\
\text { SD }\end{array}$ & $\begin{array}{r}19.04 \\
3.36\end{array}$ & $\begin{array}{r}19.26 \\
3.44\end{array}$ \\
\hline \multicolumn{3}{|c|}{ Use of Support Aids } \\
\hline $\begin{array}{l}\text { Mean } \\
\text { SD }\end{array}$ & $\begin{array}{r}25.07 \\
5.79\end{array}$ & $\begin{array}{r}26.00 \\
5.23\end{array}$ \\
\hline \multicolumn{3}{|c|}{ Self Testing } \\
\hline $\begin{array}{l}\text { Mean } \\
\text { SD }\end{array}$ & $\begin{array}{r}26.48 \\
5.60\end{array}$ & $\begin{array}{r}27.12 \\
5.14\end{array}$ \\
\hline \multicolumn{3}{|c|}{ Test Taking } \\
\hline $\begin{array}{l}\text { Mean } \\
\text { SD }\end{array}$ & $\begin{array}{r}31.29 \\
5.10\end{array}$ & $\begin{array}{r}31.25 \\
5.12\end{array}$ \\
\hline
\end{tabular}




\section{Appendix M}

Pre and Posttest Means and Standard Deviations for Methods C, B, and A; and Business and Nonbusiness Classes on LASSI Scales. Means for Method by Class by Time.

\begin{tabular}{lllllll}
\hline & \multicolumn{2}{c}{ C } & & \multicolumn{2}{c}{ A } & \\
Measure & Business & Nonbusiness & Business & Nonbusiness & Business & Nonbusiness \\
& Pre Post & Pre Post & Pre Post & Pre Post & Pre Post Pre Post \\
& 30 Subjects & 13 Subjects & 22 Subjects & 11 Subjects & 15 Subjects & 10 Subjects \\
\hline
\end{tabular}

Attitude

Mean

SD
$34.7333 .93 \quad 34.2333 .92$

3.433 .66
34.6833 .55 4.445 .80
34.9133 .55 $1.64 \quad 2.77$
$34.0032 .73 \quad 33.0031 .90$ $\begin{array}{llll}3.32 & 3.83 & 5.81 & 4.91\end{array}$

Motivation

Mean
SD

$30.3332 .13 \quad 30.90 .28 .40$ $\begin{array}{llll}422 & 3.58 & 4.93 & 5.50\end{array}$
32.5732 .23

4.724 .90
32.6931 .62

4.154 .61
32.7332 .55 5.175 .12
31.3628 .45 2.943 .62
Time Management

$\begin{array}{llll}\text { Mean } \quad 27.80 & 27.43 \quad 27.3826 .38\end{array}$

$\begin{array}{llllll}\text { SD } & & 6.51 & 6.74 & 7.93 & 6.27\end{array}$

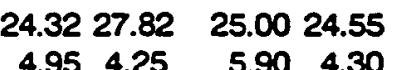

$24.5327 .67 \quad 24.5023 .60$ $\begin{array}{llll}5.29 & 4.67 & 6.29 & 6.17\end{array}$

Anxiety

Mean

SD
25.6228 .15 $7.33 \quad 6.88$
28.8230 .39 $\begin{array}{ll}5.41 & 6.12\end{array}$
29.2729 .00 3.854 .82
$27.7328 .47 \quad 25.3023 .80$ $\begin{array}{llll}5.80 & 6.37 & 4.95 & 6.03\end{array}$

Concentration

Mean $\quad 30.6330 .10$

SD $\quad 4.94 \quad 3.63$

Information Processing

$\begin{array}{lcccc}\text { Mean } & 29.83 & 28.70 & 28.08 & 28.54 \\ \text { SD } & 5.32 & 5.35 & 5.01 & 5.01\end{array}$

Selecting Main Ideas

Mean 20.0719 .90

$\begin{array}{lll}\text { SD } & 3.14 & 3.36\end{array}$

18.0818 .38

$3.80 \quad 3.25$

19.6419 .73

$2.97 \quad 3.57$

17.3618 .00

$4.30 \quad 2.86$

$18.6720 .33 \quad 18.3017 .20$

$\begin{array}{llll}2.87 & 3.31 & 3.23 & 3.68\end{array}$

Use of Support Aids

$\begin{array}{lcccc}\text { Mean } & 26.60 & 26.03 & 25.62 & 25.62 \\ \text { SD } & 5.89 & 5.36 & 5.53 & 4.63\end{array}$

24.1826 .36

4.375 .51

24.6423 .64

$6.30 \quad 5.78$

$22.6027 .00 \quad 25.9026 .50$

$6.42 \quad 6.2 n \quad 6.81 \quad 2.46$

$\frac{\text { Self Testing }}{\text { Mean }}$

Mean $27.6325 .93 \quad 27.9227 .69$

SD

5.695 .59

$4.33 \quad 5.07$

$\begin{array}{cccc}25.18 & 27.55 & 25.45 & 25.91 \\ 5.64 & 5.49 & 4.30 & 4.93\end{array}$

25.1329 .33

$6.46 \quad 4.10$

27.1027 .00

Test Taking

Mean

32.3332 .43

30.1531 .15

32.0532 .50

5.005 .01
29.6430 .09

$4.67 \quad 4.32$
$31.0731 .60 \quad 30.1025 .80$

$\begin{array}{llll}4.40 & 5.05 & 3.96 & 6.29\end{array}$

Note: $\mathbf{N}=101$. 